\title{
Hurdles and steps: Estimating demand for solar photovoltaics
}

\author{
Kenneth Gillingham \\ School of Forestry \& Environmental Studies, Department of Economics, School of Management, \\ Yale University and NBER \\ Tsvetan Tsvetanov \\ Department of Economics, University of Kansas
}

\begin{abstract}
This paper estimates demand for residential solar photovoltaic (PV) systems using a new approach to address three empirical challenges that often arise with count data: excess zeros, unobserved heterogeneity, and endogeneity of price. Our results imply a price elasticity of demand for solar PV systems of -0.65 . Counterfactual policy simulations indicate that reducing state financial incentives in half would have led to $9 \%$ fewer new installations in Connecticut in 2014. Calculations suggest a subsidy program cost of $\$ 364 / \mathrm{tCO}_{2}$ assuming solar displaces natural gas. Our Poisson hurdle approach holds promise for modeling the demand for many new technologies.

KEYwords. Count data, hurdle model, fixed effects, instrumental variables, Poisson, energy policy.
\end{abstract}

JEL CLASSification. C33, C36, Q42, Q48.

\section{INTRODUCTION}

The market for rooftop solar photovoltaic (PV) systems has been growing rapidly around the world in the past decade. In the United States, there has been an increase in new installed capacity from under 500 MW in 2008 to over 4500 MW in 2013, along with a decrease in average (preincentive) PV system prices from over $\$ 8 / \mathrm{W}$ in 2008 to just above $\$ 4 / \mathrm{W}$ in 2013 (in 2014 dollars) (Barbose, Weaver, and Darghouth (2014)). These major changes in the market have come over a period of considerable government support at both the state and federal levels, ranging from state-level rebates to a $30 \%$ federal tax credit. For example, in Connecticut (CT), the 2008-2014 average combined state and federal incentives equaled $50 \%$ of the system cost for most PV system purchasers. ${ }^{1}$ Yet

Kenneth Gillingham: kenneth.gillingham@yale.edu

Tsvetan Tsvetanov: tsvetanov@ku . edu

The authors would like to thank the Connecticut Green Bank for providing the data used in this analysis. We also thank Bryan Bollinger, CG Dong, Robert Mendelsohn, Corey Lang, Jim Sallee, Steve Sexton, Ted Juhl, Arthur van Benthem, Zhipeng Liu, and numerous seminar audiences for helpful discussions. Finally, we acknowledge funding from US Department of Energy award DE-EE0006128.

${ }^{1}$ This calculation is made based on an average system price in 2008-2014 in CT of $\$ 36,607$, average state rebate amount of $\$ 10,288$, and tax credit (taken post-incentive) of $\$ 7896$ for consumers with at least this much tax burden (all in 2014 dollars).

(C) 2019 The Authors. Licensed under the Creative Commons Attribution-NonCommercial License 4.0. Available at http://qeconomics.org. https://doi.org/10.3982/QE919 
such substantial government support is being slowly reduced in many markets throughout Europe and the United States.

This paper develops a new approach to addressing key empirical challenges in estimating demand with count data and applies this approach to model the demand for residential PV systems in CT. We use rich installation-level data over the period 2008 to 2014 to shed new light on a small, but fast-growing market that is similar to many others around the world. We estimate a price elasticity of demand for a PV system of -0.65 , a finding useful to both policymakers and firms. Policymakers are often interested in how changes in PV system prices-whether due to policy or other factors-influence the sales of PV systems. Such knowledge is essential for assessing the impacts of solar PV policies. Given the evidence that PV system installation markets are often imperfectly competitive (Bollinger and Gillingham (2016), Gillingham et al. (2016), Pless and van Benthem (2017)), firms may be able to use this elasticity to inform pricing decisions and market forecasts.

The empirical challenges that motivate our approach are threefold: possible unobserved heterogeneity at a fine geographic level, excess zeros, and endogeneity of price (due to simultaneity). Existing studies have developed count data methods that can separately address the presence of excess zeros (e.g., Pohlmeier and Ulrich (1995), Santos Silva and Windmeijer (2001), Winkelmann (2004)) or endogeneity of covariates without unobserved heterogeneity (e.g., Mullahy (1997), Windmeijer and Santos Silva (1997), Terza (1998)). Windmeijer (2008) goes further in addressing endogeneity in the presence of unobserved heterogeneity, but does not address excess zeros. This paper is the first to address all three challenges in a count data setting with clear policy significance. We use panel data on the count of annual solar PV systems installed in a Census block group. Such panel data allow us to address likely unobserved heterogeneity in environmental preferences or other block group-specific factors with fixed effects. Aggregating at a higher level would leave this unobserved heterogeneity unaddressed. However, $74 \%$ of the observations have zero values for the number of installations in a block group in a year. Thus, classic models for count data are problematic, such as the Poisson and negative binomial, which likely misspecify the underlying data generating process. Moreover, the negative binomial model cannot readily accommodate block group fixed effects and endogeneity.

To address this problem, we employ a hurdle model, which is recognized as an effective tool for dealing with the presence of excess zeros in count data settings (e.g., Cameron and Trivedi (2013)). We estimate a hurdle model based on two data generating processes: a standard logit for whether a block group has at least one adoption and a zero-truncated Poisson that models the rate of adoptions conditional on a block group having an adoption. This hurdle model has a clear behavioral interpretation in our setting: the first installation in an area is a rare event, but once there are multiple installations, peer effects may begin to influence adoption and installers can focus marketing on the area, so we have a count process. In order to tackle unobserved heterogeneity and endogeneity of the price variable, we extend the hurdle model to accommodate fixed effects and instrumental variables. 
At the basis of our approach is the conditional maximum likelihood (CMLE) estimator for fixed effects logit models introduced in a sequence of works by Rasch $(1960,1961)$, Andersen (1972), and Chamberlain (1980). Majo and van Soest (2011) show that this conditional maximum likelihood approach can also be applied to the zero-truncated Poisson framework and present an application of this in a two-period setting. We generalize the model of Majo and van Soest (2011) to a setting with an arbitrary number of periods and possible endogeneity. In contrast to Majo and van Soest (2011), our approach uses a generalized method of moments (GMM) estimator that is based on the first-order conditions of the truncated Poisson CMLE. By using a GMM approach (as in Windmeijer (2008) and several other papers), we can draw upon the established procedures for addressing endogeneity using instrumental variables. To the best of our knowledge, this instrumental variables Poisson hurdle model with fixed effects is new to the literature, and we both prove the consistency of our estimator and verify it with a Monte Carlo simulation. This approach is particularly useful for solar PV markets, but we expect that it is more broadly applicable to many other settings with similar empirical challenges, such as the demand for many early-stage technologies.

Identification in our setting is based on deviations from block group and year means in both the number of installations and PV system prices, after controlling for a variety of potential confounders and instrumenting for price. As instruments, we use a set of supply shifters: local roofing contractor wage rates and state incentives for PV systems. After controlling for income at a localized level, county-level roofer wages act as a valid contractor marginal cost shifter. Solar PV incentives in CT are given directly to the installing firm rather than the consumer, so the consumer sees the post-incentive price at the bottom of any contract to install a PV system. Thus, the incentives also act as a valid marginal cost shifter.

Our preferred estimate of the price elasticity of PV system demand of -0.65 is the first estimate we are aware of for CT. This result is comparable to the existing literature, which uses data from California and very different empirical strategies. For example, Rogers and Sexton (2014) find a rebate elasticity of approximately -0.4 , while Hughes and Podolefsky (2015) find an estimate of approximately -1.2. In contrast to the previous papers, which both use reduced form approaches, Burr (2014) estimates a dynamic discrete choice model of demand, but does not specifically estimate a price elasticity of demand. The dynamic discrete choice approach may seem well-suited for our context, since subsidies may be changing over time and a household usually only installs a solar system once (although a household can always add capacity later if there is available roof space). However, we provide survey and descriptive evidence in Online Appendix A of the Supplemental Material (Gillingham and Tsvetanov (2019)) suggesting that solar $\mathrm{PV}$ demand in CT is more similar to the many other contexts where consumers do not appear to treat adoption as a dynamic "buy-or-wait" decision.

Using our results, we perform policy counterfactual simulations to examine the impact of state financial incentives and permitting policies on PV system adoption. We first perform a simple analysis of the pass-through of the incentives to consumers, following Sallee (2011), and find the pass-through rate of $84 \%$. Our simulation results suggest, under a 50\% reduction of all financial incentives for purchasing PV systems, the number 
TABLE 1. Timeline of pre-RSIP solar rebates.

\begin{tabular}{lccccc}
\hline Rebate Structure & Program Opens & Change & Change & Closed & Reopened \\
\hline Date & July 1,2004 & Jan 29,2007 & Oct 27,2008 & Nov 19, 2008 & May 18, 2009 \\
$\leq 5 \mathrm{~kW}$ & $\$ 5.00 / \mathrm{W}$ & $\$ 5.00 / \mathrm{W}$ & $\$ 4.00 / \mathrm{W}$ & - & $\$ 1.75 / \mathrm{W}$ \\
$>5 \mathrm{~kW}$ and $\leq 10 \mathrm{~kW}$ & $\$ 0.00 / \mathrm{W}$ & $\$ 4.30 / \mathrm{W}$ & $\$ 2.50 / \mathrm{W}$ & - & $\$ 1.25 / \mathrm{W}$ \\
\hline
\end{tabular}

Note: Source: The Connecticut Green Bank.

of new installations in CT in 2014 would have been $9 \%$ less than observed. This would result in up to 1.3 MW less added PV capacity in 2014. Simple calculations suggest a costeffectiveness of the program of $\$ 364$ per avoided ton of $\mathrm{CO}_{2}(\$ 594$ if the federal tax credit is included), assuming that solar power displaces natural gas-fired generation.

The remainder of this paper is structured as follows. Section 2 provides a background on policies in CT targeted at stimulating solar demand. Section 3 describes the data used in our analysis. Sections 4 and 5 outline the estimation methodology. Section 6 presents our empirical results. Section 7 presents the pass-through analysis, counterfactual policy simulations, and a discussion of cost-effectiveness and welfare. Finally, Section 8 concludes.

\section{BACKGROUND ON SOLAR PV POLICIES IN CONNECTICUT}

Despite receiving fewer hours of sun than more southerly regions, ${ }^{2}$ CT has a robust and growing market for solar PV systems, due to high electricity prices, many owneroccupied homes, and considerable state support for PV systems. A $\$ 5$ per watt (W) rebate for residential solar PV systems (up to $5 \mathrm{~kW}$ ) was available in CT as early as 2004, as shown in Table 1. The structure of incentives changed on July 1, 2011, with the passage of Connecticut Public Act 11-802, directing the newly established CT Energy Finance and Investment Authority, which has since been renamed the Connecticut Green Bank (CGB), to develop a residential solar investment program that would result in at least 30 MW of new residential PV installations by the end of 2022 (Shaw, Fahey, and Solomon (2014))..$^{3}$

Starting on March 2, 2012, two types of financial incentives were offered under the "Residential Solar Investment Program" (RSIP). For households that purchase a solar PV system, CT offers an upfront rebate, under an "expected performance based buy-down" (EPBB) program (replaced by the similar "homeowner performance based incentive" (HOPBI) rebate program after July 11, 2014). The rebate per $W$ decreases based on the size of the system, with lower incentives per $\mathrm{W}$ for systems larger than $5 \mathrm{~kW}$ and even lower for systems larger than $10 \mathrm{~kW}$. Most systems in CT fall under this incentive program until near the end of our time period, when a higher percentage of systems are not purchased outright. For such third party-owned systems (e.g., installed under a solar lease or power purchase agreement), CT offers quarterly incentive payments based on

\footnotetext{
${ }^{2}$ See solar insolation maps at http://www.nrel.gov/gis/solar.html.

${ }^{3}$ This target had already been reached by the end of 2014. See http://www.ctcleanenergy.com.
} 
TABLE 2. Residential solar investment program timeline.

\begin{tabular}{lcccccc}
\hline Incentive Type & Step 1 & Step 2 & Step 3 & Step 4 & Step 5 & Step 6 \\
\hline $\begin{array}{l}\text { EPBB } / \text { HOPBI } \\
\text { Start Date }\end{array}$ & March 2, 2012 & May 18, 2012 & Jan 4, 2013 & Jan 6, 2014 & Sept 1, 2014 & Jan 1, 2015 \\
Incentive Design: & & & & & & \\
$\leq 5 \mathrm{~kW}$ & $\$ 2.450 / \mathrm{W}$ & $\$ 2.275 / \mathrm{W}$ & $\$ 1.750 / \mathrm{W}$ & $\$ 1.250 / \mathrm{W}$ & $\$ 0.800 / \mathrm{W}$ & $\$ 0.675 / \mathrm{W}$ \\
$>5 \mathrm{~kW}$ and $\leq 10 \mathrm{~kW}$ & $\$ 1.250 / \mathrm{W}$ & $\$ 1.075 / \mathrm{W}$ & $\$ 0.550 / \mathrm{W}$ & $\$ 0.750 / \mathrm{W}$ & $\$ 0.800 / \mathrm{W}$ & $\$ 0.675 / \mathrm{W}$ \\
$>10 \mathrm{~kW}$ and $\leq 20 \mathrm{~kW}$ & - & - & - & - & $\$ 0.400 / \mathrm{W}$ & $\$ 0.400 / \mathrm{W}$ \\
PBI & & & & & & \\
Start Date & March 2, 2012 & May 18,2012 & April 1,2013 & Jan 6, 2014 & Sept 1, 2014 & Jan 1,2015 \\
Incentive Design: & & & & & & \\
$\leq 10 \mathrm{~kW}$ & $\$ 0.300 / \mathrm{kWh}$ & $\$ 0.300 / \mathrm{kWh}$ & $\$ 0.225 / \mathrm{kWh}$ & $\$ 0.125 / \mathrm{kWh}$ & $\$ 0.180 / \mathrm{kWh}$ & $\$ 0.080 / \mathrm{kWh}$ \\
$>10 \mathrm{~kW}$ and $\leq 20 \mathrm{~kW}$ & - & - & - & - & $\$ 0.600 / \mathrm{kWh}$ & $\$ 0.060 / \mathrm{kWh}$ \\
\hline
\end{tabular}

Note: Source: The Connecticut Green Bank.

production (in kWh) over 6 years, under a "performance-based incentive" (PBI) program (Shaw, Fahey, and Solomon (2014)). All incentives are being reduced over time in a series of steps as the solar PV market grows. Unlike other states, where learning-by-doing was an explicit policy motivation (Bollinger and Gillingham (2016)), in CT this declining step schedule is primarily motivated by budget constraints and a broad desire for a self-sustaining market. Table 2 provides details of the programs and the step schedule. Online Appendix A gives more detail on the path of subsidies and consumer adoption of solar PV, providing evidence that the subsidy declines were unanticipated by consumers.

Besides direct financial incentives, CT has several additional programs to promote solar PV systems. One program is "net metering," which allows owners of solar PV systems to return excess generated electricity to the grid, offsetting electricity that is used during times of nongeneration, so the final electricity bill includes a charge for only the net electricity usage. PV system owners can also carry over credits for excess production for up to 1 year. On March 31 of each year, the utility pays the PV system owners any net excess generation remaining at the avoided cost of wholesale electricity (a lower rate than the retail rate).

Another program in CT is an effort starting in 2011 to streamline municipality and utility permitting, inspection, and interconnection processes. Several municipalities in CT have reduced their permitting costs and reduced the permitting time in response to this effort. Similar efforts have occurred in a number of other states, such as Arizona, California, and Colorado (CEFIA (2013)).

Perhaps the most important nonrebate program for solar PV system adoption in CT is the CGB-sponsored "Solarize CT" grassroots marketing program in select municipalities. ${ }^{4}$ Solarize CT involves local campaigns with a municipality-chosen installer, roughly 20-week time frame, and prenegotiated group discount pricing for all PV system installations in the town. According to Gillingham and Bollinger (2017), this program led to a substantial increase in demand in these municipalities: on average roughly 30 addi-

\footnotetext{
${ }^{4}$ Solarize CT is funded by foundations, ratepayers, and other grants.
} 
tional installations per municipality over the length of the program. The program is also associated with a roughly $\$ 0.40$ to $\$ 0.50$ per $\mathrm{W}$ decrease in installation prices.

\section{DATA}

Our primary dataset contains nearly all residential solar PV system installations in CT from the period 2008-2014. Each installation that receives a rebate in the two major investor-owned electric utility regions in CT, United Illuminating and Eversource Energy (formerly Connecticut Light \& Power) is entered into a database by CGB, with information on price, rebates granted, system size (in $\mathrm{kW}$ ), technical characteristics, financing arrangements, address, date of application processing, and date of installation. ${ }^{5}$ Until late 2014, there were few third party-owned (TPO) systems in CT (i.e., solar leases or power-purchase agreements) and the price data for these TPO systems are well known to be less reliable than owned-system price data. Thus, we exclude these TPO systems from our primary analysis. ${ }^{6}$ Our raw dataset contains 5070 residential PV installations approved for the rebate by the CGB between January 1, 2008 and December 31, 2014.

We geocode the installations and match each to the U.S. Census block group they reside in. We then collect U.S. Census data at the block group level from the 2006-2010, 2007-2011, 2008-2012, and 2009-2013 waves of the American Community Survey (ACS). We include data on total population, median household income, median age, and education level. We obtain a measure of block group population density by dividing population by land area. To generate panel data for each variable, we use the average value for each variable across all waves available for that year. So, for example, the value for population in 2010 would be the average of the 2006-2010, 2007-2011, 2008-2012, and 2009-2013 values for this variable. We use the 2009-2013 values for $2014 .^{7}$ In addition to Census data, we also draw town-level voting registration data from the Office of CT's Secretary of the State (http://portal.ct.gov/sots) for each year in our study period. Finally, we bring in annual county-level roofing contractor wage data from the U.S. Bureau of Labor Statistics (http://www.bls.gov).

\subsection{Preparation of the panel dataset}

Due to the possibility of unobserved heterogeneity at the localized level, we convert our data to a panel dataset, where an observation is at the Census block group-year level. This leads to a balanced panel of 10,738 observations in 1534 block groups. For each

\footnotetext{
${ }^{5}$ The only other utilities in CT are small municipal utilities in Bozrah, Norwich, and Wallingford (Graziano and Gillingham (2015)).

${ }^{6}$ As a robustness check, we also analyze the full dataset of purchased and third-party-owned (TPO) systems, controlling for third party ownership in the regressions. The results, presented in Online Appendix E in the Supplemental Material (Gillingham and Tsvetanov (2019)), should be interpreted with great caution due to the known issues with over-reporting of TPO system prices. They are suggestive of a different consumer decision-process for TPO systems.

${ }^{7}$ We also employed an alternative approach, using only the mid-year of each ACS wave and interpolating for all missing years, but this made no practical difference to our results. More generally, as shown in Section 6.2, our results are also robust to the exclusion of all demographic variables.
} 
block group-year, we take the average of the system price, system size, and incentive level granted. We also create an indicator variable for a Solarize campaign occurring in the given block group-year.

Using this panel dataset for our empirical analysis necessitates one further step. Many observations refer to block group-year combinations where there are no installations. In fact, our hurdle model approach is motivated by these excess zeros in our dataset. However, we still have to determine the relevant installation price, system size, and incentive for observations with no recorded contracts. This is a common issue in the empirical literature and we take a conservative stance by examining two different approaches.

In our primary approach, we fill in the missing price and other variables with the average annual value for the same municipality, and if this is not possible, we use the average annual value within the county of the installation. Given that our adoption data in these block groups is censored at zero, this approach may underestimate the price. Thus, as shown in Section 6.2, we perform several robustness checks and find that our results are robust to this choice. Our post-incentive PV system price per W variable is based on the ratio of the average block group-year PV system prices and the average system size.

\subsection{Trends and summary statistics}

Figure 1 displays the overall trend in installations and PV system prices (in 2014 dollars) during our study period. Between 2008 and 2014, the real average (post-incentive) price falls by more than $40 \%$, with a brief spike in 2009. This spike in the post-incentive price is commonly attributed to a roughly $50 \%$ drop in the incentive between 2008 and 2009. Consistent with larger trends in the global PV market (Barbose, Darghouth, Weaver and Wiser (2013)), real installation costs have been steadily decreasing during the entire study period, while the efficiency of panels and quality of installations remained relatively constant. Figure 1 also shows a substantial increase in PV system installations after 2011. Some of this increase after 2011 consists of installations under Solarize programs, which involve both lower prices and additional solar marketing.

Table 3 presents summary statistics for our panel dataset of 10,738 block group-year observations. The number of PV system installations is a count variable, with a mean of 0.48 and a variance of 1.19 . Hence, these data exhibit clear overdispersion relative to standard count models, such as the Poisson model, in which an underlying assumption is the equality of mean and variance of the count variable (see Section 4.2). Figure 2 reveals why this might be the case: the distribution of installations in a block group in a given year is very strongly skewed, with most of the mass (over 74\%) centered at zero. This visually illustrates the issue of excess zeros in our dataset. Table 4 presents summary statistics for the truncated dataset with positive installations. Comparing Tables 3 and 4 reveals some differences. Most notably, there is a much stronger presence of Solarize campaigns in the truncated sample (12\% versus $6 \%)$. The truncated sample has lower average population density, consistent with Graziano and Gillingham (2015), who show that most installations in CT occur in suburban or rural areas. This sample also 


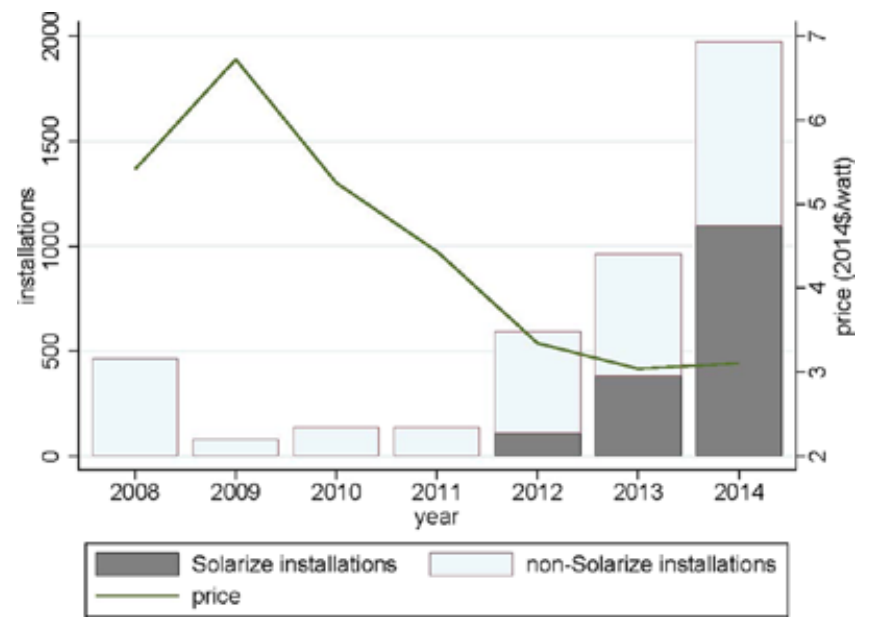

FIgURE 1. Trends in installations and average post-incentive system price.

TABLE 3. Summary statistics for the full sample.

\begin{tabular}{lcccc}
\hline Variable & Mean & St. Dev. & Min & Max \\
\hline Number of PV installations & 0.4781 & 1.0891 & 0 & 20 \\
System capacity $(\mathrm{kW})$ & 6.972 & 1.8417 & 0.7 & 22.1 \\
Post-incentive system price $(\$ / \mathrm{W})$ & 3.7645 & 1.4369 & 0.0171 & 20.5824 \\
Solarize campaign & 0.0595 & 0.2366 & 0 & 1 \\
Population density (per $\mathrm{km}^{2}$ ) & 853.651 & 1249.742 & 0 & 21,784 \\
Median household income (in 1000\$/year) & 88.7752 & 41.7775 & 2.499 & 250.001 \\
Median age & 42.6938 & 7.0762 & 14.8 & 80.6 \\
\% population above 25 with some college or college degree & 46.7736 & 9.9282 & 0 & 81.203 \\
\% population above 25 with graduate or professional degree & 18.3589 & 12.1701 & 0 & 80.7786 \\
\% Republican voters & 21.9084 & 7.8536 & 3.69 & 51.14 \\
\% Democrat voters & 34.0913 & 10.5664 & 16.92 & 72.3 \\
Incentive level $(\$ / W)$ & 3.5288 & 2.0203 & 0.6824 & 6.4879 \\
Roofing contractor wage (\$/week) & 1031.203 & 171.964 & 548.894 & 1312.658 \\
\hline
\end{tabular}

Note: All variables have 10,738 observations. All dollars in 2014 dollars.

features slightly larger systems, likely because it more heavily samples block groups that are slightly wealthier and have a greater unobserved preference for PV systems.

\section{Empirical SPECification: Preliminaries}

Let $Y_{i t}$ denote the number of PV installations in block group $i$ purchased in year $t$. We use $\boldsymbol{W}_{i t}$ to denote a vector containing the installation price $p_{i t}$ and demand shifters. Demand for solar is represented by the following general function:

$$
Y_{i t}=D_{i t}\left(\boldsymbol{W}_{i t}, \boldsymbol{\Theta}\right)
$$




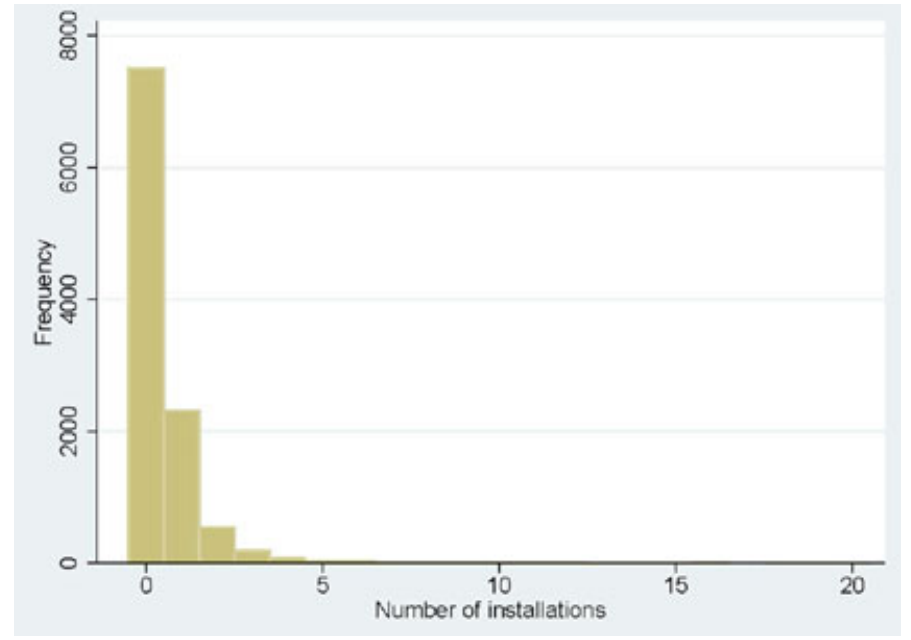

FIgURE 2. Histogram of the count of installations in the full sample.

TABLE 4. Summary statistics for the subsample with positive installations.

\begin{tabular}{lcccc}
\hline Variable & Mean & St. Dev. & Min & Max \\
\hline Number of PV installations & 1.5855 & 1.4758 & 1 & 20 \\
System capacity $(\mathrm{kW})$ & 7.2405 & 2.5195 & 0.7 & 22.1 \\
Post-incentive system price $(\$ / \mathrm{W})$ & 3.8945 & 1.4433 & 0.0171 & 19.0565 \\
Solarize campaign & 0.1167 & 0.3212 & 0 & 1 \\
Population density (per $\mathrm{km}^{2}$ ) & 607.418 & 943.207 & 0 & $14,530.95$ \\
Median household income (in 1000\$/year) & 91.8035 & 40.2957 & 10.833 & 250.001 \\
Median age & 43.3453 & 6.795 & 17.6 & 79.2 \\
\% population above 25 with some college or college degree & 47.4923 & 9.4677 & 0 & 77.8978 \\
\% population above 25 with graduate or professional degree & 19.2437 & 11.89 & 0 & 80.7786 \\
\% Republican voters & 22.7355 & 7.1854 & 3.69 & 50.19 \\
\% Democrat voters & 32.5461 & 9.2511 & 16.92 & 71.78 \\
Incentive level (\$/W) & 3.0427 & 2.0825 & 0.6824 & 6.4879 \\
Roofing contractor wage (\$/week) & 1010.557 & 175.821 & 548.894 & 1312.658 \\
\hline
\end{tabular}

Note: All variables have 3,238 observations. All dollars in 2014 dollars.

where $\Theta$ is a vector of parameters. Before we describe the Poisson hurdle model, which is our preferred empirical specification, we first briefly review two alternative specifications, linear and Poisson, to lay the groundwork.

\subsection{Linear}

In this specification, $D_{i t}(\cdot)$ is modeled as a linear function and (1) becomes

$$
Y_{i t}=\boldsymbol{W}_{i t}^{\prime} \boldsymbol{\Theta}+\varepsilon_{i t},
$$

where $\varepsilon_{i t}$ denotes an idiosyncratic error term. We can expand (2) further as $Y_{i t}=\alpha_{i}+$ $\boldsymbol{w}_{i t}^{\prime} \boldsymbol{\theta}+\mu_{t}+\varepsilon_{i t}$, where $\alpha_{i}$ captures block group-specific effects, $\mu_{t}$ is a year fixed effect that 
captures time-varying demand shocks common across block groups, and $\boldsymbol{w}_{i t}$ contains all remaining observed regressors.

The advantage of using a linear model is that it can easily accommodate fixed effects to control for region-specific unobserved heterogeneity. Furthermore, the linear model also allows for the straightforward implementation of an instrumental variables procedure to address the endogeneity of prices. However, it is well recognized in the literature (e.g., King (1988), Wooldridge (2002)) that a linear model is poorly suited for a count data setting. A linear model not only misspecifies the count data generating process, but it also often predicts negative and noninteger outcome values.

\subsection{Poisson}

In this specification, we model the data generating process as a Poisson process, which is perhaps a better model for our count data. More specifically, if $Y_{i t}$ is modeled as a Poisson random variable with parameter $\lambda_{i t}>0$, its probability mass function, denoted by $P o$, is given by: $\operatorname{Po}\left(y \mid \lambda_{i t}\right)=\operatorname{Pr}\left[Y_{i t}=y \mid \lambda_{i t}\right]=\frac{\lambda_{i t}^{y} e^{-\lambda_{i t}}}{y !}$, where $y=0,1,2, \ldots, \infty$. Furthermore, it follows that

$$
\mathrm{E}\left[Y_{i t} \mid \lambda_{i t}\right]=\operatorname{Var}\left[Y_{i t} \mid \lambda_{i t}\right]=\lambda_{i t},
$$

that is, the conditional mean and variance of the Poisson random variable are equal. The parameter $\lambda_{i t}$ is modeled as an exponential function of the covariates: $\lambda_{i t}=e^{\boldsymbol{W}_{i t}^{\prime} \boldsymbol{\Theta}}$.

Therefore, in this specification, the conditional expectation of (1) is

$$
\mathrm{E}\left[Y \mid \boldsymbol{W}_{i t}, \boldsymbol{\Theta}\right]=e^{\boldsymbol{W}_{i t}^{\prime} \boldsymbol{\Theta}} \equiv e^{\alpha_{i}+\boldsymbol{w}_{i t}^{\prime} \boldsymbol{\theta}+\mu_{t}}
$$

To facilitate discussion of this common model, we can then further rewrite (4) using $\boldsymbol{X}$ to denote the vector of observed regressors and time dummies, and $\boldsymbol{\delta}$ to denote the vector of all slope parameters (i.e., excluding the time-invariant fixed effects parameters):

$$
\mathrm{E}\left[Y \mid \boldsymbol{X}_{i t}, \boldsymbol{\delta}, \alpha_{i}\right]=e^{\alpha_{i}+\boldsymbol{X}_{i t}^{\prime} \boldsymbol{\delta}} .
$$

The presence of individual-specific fixed effects usually poses a challenge in the estimation of nonlinear panel models, such as the one presented in equation (5), since these parameters cannot be eliminated from the model through any of the standard transformations used in linear models. If heterogeneity is left completely unrestricted and the model is estimated directly with the fixed parameters included, the estimates would suffer from the "incidental parameters problem" first noted by Neyman and Scott (1948). The problem arises since the estimator of the fixed effects parameter $\alpha_{i}$ is based only on the number of observations for each $i \in\{1, \ldots, N\}$, and that number remains fixed even as $N \rightarrow \infty$. Hence, the estimator $\hat{\alpha}_{i}$ is inconsistent, while the estimator of $\hat{\boldsymbol{\delta}}$ is only consistent if it can be expressed separately from $\hat{\alpha}_{i}$. Fortunately, as shown by Blundell, Griffith, and Windmeijer (2002), the latter is the case in the Poisson panel model. In particular, when this model is estimated by maximizing the log-likelihood function, the first-order conditions can be rearranged so that $\hat{\boldsymbol{\delta}}$ does not depend on the estimates 
of the fixed effects coefficients. Therefore, the maximum likelihood estimator (MLE) for $\boldsymbol{\delta}$ in our model with block group-specific constants does not suffer from the incidental parameters problem. ${ }^{8}$

Yet even with time-invariant unobserved heterogeneity accounted for, $\hat{\boldsymbol{\delta}}_{M L E}$ may still be inconsistent due to the endogeneity of the price variable in $\boldsymbol{W}_{i t}$. One potential solution to the presence of an endogenous regressor in a Poisson model is the control function (CF) approach. Imbens and Wooldridge (2007) lay out a CF approach for addressing endogeneity in a cross-sectional Poisson model, which can be easily generalized to a panel data setting.

First, reexpress the vector of covariates as $\boldsymbol{W}=\left(p, \boldsymbol{Z}_{1}\right)^{\prime}$ and the corresponding vector of parameters as $\boldsymbol{\Theta}=(\gamma, \boldsymbol{\Gamma})^{\prime}$. Furthermore, let $\boldsymbol{Z}$ be a vector of exogenous variables, such that $\boldsymbol{Z}_{1} \subset \boldsymbol{Z}$. Combining (3) with the definition of $\lambda_{i t}$ and dropping all subscripts for simplicity, we can flexibly rewrite the conditional mean as

$$
\mathrm{E}[Y \mid \boldsymbol{Z}, p, \zeta]=\exp \left(\gamma p+\boldsymbol{Z}_{1}^{\prime} \boldsymbol{\Gamma}+\zeta\right),
$$

where $\zeta$ is an unobserved component of the conditional expectation that is correlated with $p$. Let the endogenous variable $p$ be written as

$$
p=Z^{\prime} \Pi+r
$$

Applying the law of iterated expectations to (6) and (7),

$$
\mathrm{E}[Y \mid \boldsymbol{Z}, p]=\mathrm{E}[Y \mid \boldsymbol{Z}, r]=\mathrm{E}[\mathrm{E}[Y \mid \boldsymbol{Z}, \zeta, r] \mid \boldsymbol{Z}, r]=\exp \left(\gamma p+\boldsymbol{Z}_{1}^{\prime} \boldsymbol{\Gamma}\right) \mathrm{E}[\exp (\zeta) \mid \boldsymbol{Z}, r] .
$$

Note that both $\zeta$ and $r$ are independent of $\boldsymbol{Z}$. The standard assumption here is joint normality of $\zeta$ and $r$, and under this assumption it can be shown that $\mathrm{E}[\exp (\zeta) \mid r]=\exp (\rho r)$ for some scalar $\rho$. Hence, (8) becomes $\mathrm{E}[Y \mid \boldsymbol{Z}, p]=\exp \left(\gamma p+\boldsymbol{Z}_{1}^{\prime} \boldsymbol{\Gamma}+\boldsymbol{\rho} r\right)=\exp \left(\boldsymbol{W}^{\prime} \boldsymbol{\Theta}+\boldsymbol{\rho} r\right)$, which suggests a straightforward two-stage estimation procedure. In the first stage, we estimate a linear regression of price on all excluded and included instruments in order to obtain the residual $\hat{r}$. In the second stage, we estimate a Poisson model with $\boldsymbol{W}$ and $\hat{r}$ as covariates using MLE, as described earlier. Of course, since this is a two-stage procedure, bootstrapping is the easiest way to obtain valid standard errors.

The Poisson model can thus be used to address unobserved heterogeneity with fixed effects and endogeneity of price. Moreover, it is likely a much better model for count data than the linear specification. However, by virtue of its underlying distribution, the Poisson model predicts that only a small proportion of all counts in the data equal zero

\footnotetext{
${ }^{8}$ Note that if the Poisson model contains unobserved market-level demand shocks that vary both crosssectionally and by time, the corresponding parameters $\alpha_{i t}$ can no longer be substituted out in the MLE's first-order conditions in a way that would allow solving separately for $\boldsymbol{\delta}$. Consistent estimation of $\boldsymbol{\delta}$ would then require integrating out the demand shocks. Interestingly, such a random Poisson model, in which the shocks exhibit substantial variance, can produce a large number of zero outcomes and overdispersion relative to the standard Poisson distribution, which is consistent with our data. Nonetheless, we demonstrate in Online Appendix B.1 in the Supplemental Material (Gillingham and Tsvetanov (2019)) by simulating a random Poisson model that even in that setting the hurdle model provides very close estimates to the true elasticities. We thank an anonymous referee for pointing us to this finding.
} 
and is likely misspecified when there are excess zeros in the outcome variable, so the finite-sample bias from running quasi-maximum likelihood would be expected to be large.

\section{EMPIRICAL SPECIFICATION: HuRdLE MOdEL}

\subsection{General form}

In situations with very large numbers of zeros, the data generating process is perhaps better thought of as a two-stage process. A hurdle model, originally formulated in Mullahy (1986), is designed to model such a two-stage process. ${ }^{9}$ The first stage determines whether the count variable has a zero or positive realization. A positive realization means that the "hurdle" is crossed, in which case the exact outcome value is modeled by a truncated count distribution. The two stages are functionally independent (Cameron and Trivedi (2013)). For a given nonnegative count variable $Y$, let the first-stage process be driven by a distribution function $f_{1}$, while the second stage governed by $f_{2}$. Then the complete distribution of $Y$ is given by

$$
\operatorname{Pr}(Y=y)= \begin{cases}f_{1}(0) & \text { if } y=0 \\ \left(1-f_{1}(0)\right) f_{2}(y) & \text { if } y=1,2, \ldots, \infty\end{cases}
$$

It is common to model the first stage using a logistic distribution, that is, $f_{1}=$ $1-\operatorname{Pr}[Y>0]$, where $\operatorname{Pr}[Y>0]$ is estimated through a logit regression model, and the second stage as a zero-truncated Poisson, that is, $f_{2}=\frac{P o(y)}{(1-P o(0))}$ (e.g., Min and Agresti (2005), Gallop, Rieger, McClintock and Atkins (2013), Neelon, Ghosh, and Loebs (2013)). Depending on the setting, the explanatory variables in the first- and second-stage regressions may differ.

Adapting this framework to our setting,

$$
\operatorname{Pr}\left[Y_{i t}>0 \mid \boldsymbol{W}_{i t}, \boldsymbol{\Theta}_{1}\right]=\frac{e^{\boldsymbol{W}_{i t}^{\prime} \boldsymbol{\Theta}_{1}}}{1+e^{\boldsymbol{W}_{i t}^{\prime} \boldsymbol{\Theta}_{1}}}, \quad f_{2}\left(y \mid \lambda_{i t}\right)=\frac{\lambda_{i t}^{y}}{y !\left(e^{\lambda_{i t}}-1\right)} \quad \text { and } \quad \lambda_{i t}=e^{\boldsymbol{W}_{i t}^{\prime} \boldsymbol{\Theta}_{2}}
$$

Note that while we expect the same determinants to play a role in both stages of the demand model, there is no behavioral reason to presume $a$ priori that the effects of these determinants would be identical. Therefore, we allow $\boldsymbol{\Theta}_{1}$ to be different than $\boldsymbol{\Theta}_{2}$.

\footnotetext{
${ }^{9}$ A zero-inflated Poisson (ZIP) model is a similar model, but not as readily extendable to a panel data context with fixed effects and instrumental variable estimation. Gilles and Kim (2017) developed a quasiconditional likelihood method for estimating ZIP with fixed effects only in the count part that is consistent under strict exogeneity of all regressors. Kitazawa (2014) derived moment conditions that allow for the estimation of a fixed effects ZIP model with exogenous regressors in the logit component and predetermined explanatory variables in the Poisson component.
} 
Let $\iota_{i t}=I\left(Y_{i t}>0\right)$, where $I(\cdot)$ denotes the indicator function. The log-likelihood function of this model can be expressed as follows:

$$
\begin{aligned}
L\left(\boldsymbol{\Theta}_{1}, \boldsymbol{\Theta}_{2}\right) & \\
= & \sum_{i=1}^{N} \sum_{t=1}^{T}\left\{\left(1-\iota_{i t}\right) \log \left[\frac{1}{1+\exp \left(\boldsymbol{W}_{i t}^{\prime} \boldsymbol{\Theta}_{1}\right)}\right]+\iota_{i t} \log \left[\frac{\exp \left(\boldsymbol{W}_{i t}^{\prime} \boldsymbol{\Theta}_{1}\right)}{1+\exp \left(\boldsymbol{W}_{i t}^{\prime} \boldsymbol{\Theta}_{1}\right)}\right]\right\} \\
& +\sum_{i=1}^{N} \sum_{t=1}^{T}\left\{\iota_{i t}\left[Y_{i t} \boldsymbol{W}_{i t}^{\prime} \boldsymbol{\Theta}_{2}-\log \left(Y_{i t} !\right)-\log \left(\exp \left(\exp \left(\boldsymbol{W}_{i t}^{\prime} \boldsymbol{\Theta}_{2}\right)\right)-1\right)\right]\right\} \\
\equiv & L^{L}\left(\boldsymbol{\Theta}_{1}\right)+L^{P}\left(\boldsymbol{\Theta}_{2}\right),
\end{aligned}
$$

where $L^{L}\left(\boldsymbol{\Theta}_{1}\right)$ is the log-likelihood function for the logit model and $L^{P}\left(\boldsymbol{\Theta}_{2}\right)$ is the loglikelihood for the truncated Poisson model. Therefore, maximizing $L\left(\boldsymbol{\Theta}_{1}, \boldsymbol{\Theta}_{2}\right)$ is equivalent to maximizing the two terms separately, which implies that estimating the hurdle model effectively reduces to separately estimating a binary logit model and a zerotruncated Poisson model.

This model is convenient both for estimation of the parameters and for estimation of the price elasticity of demand. To see this, first note that the conditional mean of the outcome variable in this model is given by

$$
\begin{aligned}
\mathrm{E}\left[Y_{i t} \mid \boldsymbol{W}_{i t}, \boldsymbol{\Theta}\right] & =\operatorname{Pr}\left[Y_{i t}>0 \mid \boldsymbol{W}_{i t}, \boldsymbol{\Theta}_{1}\right] \mathrm{E}^{P}\left[Y_{i t} \mid \boldsymbol{W}_{i t}, \boldsymbol{\Theta}_{2}\right] \\
& =\frac{\exp \left(\boldsymbol{W}_{i t}^{\prime} \boldsymbol{\Theta}_{1}\right)}{1+\exp \left(\boldsymbol{W}_{i t}^{\prime} \boldsymbol{\Theta}_{1}\right)} \frac{\lambda_{i t}}{1-\exp \left(-\lambda_{i t}\right)},
\end{aligned}
$$

where $\boldsymbol{\Theta}=\left(\boldsymbol{\Theta}_{1}, \boldsymbol{\Theta}_{2}\right)^{\prime}$ and $\mathrm{E}^{P}[\cdot] \equiv \mathrm{E}\left[\cdot \mid Y_{i t}>0\right]$ is the mean in the truncated Poisson model. Then the price elasticity $\eta$ at the mean values of $p$ and $Y$ can be derived through the following expression:

$$
\eta=\frac{\partial\left[\mathrm{E}\left[Y_{i t}\right]\right]}{\partial p_{i t}} \frac{\mathrm{E}\left[p_{i t}\right]}{\mathrm{E}\left[Y_{i t}\right]}=\frac{\partial\left[\operatorname{Pr}\left[Y_{i t}>0\right]\right]}{\partial p_{i t}} \frac{\mathrm{E}\left[p_{i t}\right]}{\operatorname{Pr}\left[Y_{i t}>0\right]}+\frac{\partial\left[\mathrm{E}^{P}\left[Y_{i t}\right]\right]}{\partial p_{i t}} \frac{\mathrm{E}^{P}\left[p_{i t}\right]}{\mathrm{E}^{P}\left[Y_{i t}\right]} \equiv \eta^{L}+\eta^{P} .
$$

In other words, $\eta$ is a sum of the price elasticity from the logit and truncated Poisson components of the hurdle model.

An important characteristic of this model is that, unlike the Poisson specification, it can accommodate both overdispersion and underdispersion in the full dataset. In fact, it can be shown that $\operatorname{Var}\left[Y_{i t} \mid \boldsymbol{W}_{i t}, \boldsymbol{\Theta}\right]=\mathrm{E}\left[Y_{i t} \mid \boldsymbol{W}_{i t}, \boldsymbol{\Theta}\right]+\mathrm{E}\left[Y_{i t} \mid \boldsymbol{W}_{i t}, \boldsymbol{\Theta}\right]\left(\lambda_{i t}-\mathrm{E}\left[Y_{i t} \mid \boldsymbol{W}_{i t}, \boldsymbol{\Theta}\right]\right)$. Therefore, depending on the relative magnitudes of $\lambda_{i t}$ and $\mathrm{E}\left[Y_{i t} \mid \boldsymbol{W}_{i t}, \boldsymbol{\Theta}\right]$, the model could result in $\mathrm{E}\left[Y_{i t} \mid \boldsymbol{W}_{i t}, \boldsymbol{\Theta}\right] \leq \operatorname{Var}\left[Y_{i t} \mid \boldsymbol{W}_{i t}, \boldsymbol{\Theta}\right]$ or vice versa. In particular, $\mathrm{E}\left[Y_{i t} \mid \boldsymbol{W}_{i t}, \boldsymbol{\Theta}\right]$ in (10) is a linear function of $\operatorname{Pr}\left[Y_{i t}>0\right]$, so an excessive number of zero outcomes implies that $\operatorname{Pr}\left[Y_{i t}>0\right]$ (and, hence, $\mathrm{E}\left[Y_{i t} \mid \boldsymbol{W}_{i t}, \boldsymbol{\Theta}\right]$ ) is relatively small, which leads to overdispersion relative to the Poisson model.

Thus, the hurdle model is a promising approach for our setting. But the challenge of handling unobserved heterogeneity and endogeneity remains. Other approaches, such 
as the negative binomial model, can only handle an extensive set of fixed effects and endogeneity with great difficulty and restrictive assumptions. Furthermore, while studies have extended the traditional Poisson model to accommodate individual-specific fixed effects and instrumental variables (e.g., Windmeijer (2008)), there is little in the current literature on such extensions of the hurdle model.

\subsection{Fixed effects}

As suggested by equation (9), estimating the hurdle model is equivalent to separately estimating a logit model and truncated Poisson model. This allows us to address the challenge of accommodating block group fixed effects in each of the two parts of the hurdle model.

Logit With fixed effects, the logit model becomes

$$
\begin{aligned}
\operatorname{Pr}\left[Y_{i t}>0 \mid \boldsymbol{W}_{i t}, \boldsymbol{\Theta}_{1}\right] & =\operatorname{Pr}\left[\iota_{i t}=1 \mid \boldsymbol{W}_{i t}, \boldsymbol{\Theta}_{1}\right] \\
& =\frac{\exp \left(\alpha_{i}^{L}+\boldsymbol{w}_{i t}^{\prime} \boldsymbol{\theta}_{1}+\mu_{t}^{L}\right)}{1+\exp \left(\alpha_{i}^{L}+\boldsymbol{w}_{i t}^{\prime} \boldsymbol{\theta}_{1}+\mu_{t}^{L}\right)} \\
& \equiv \frac{b_{i} \exp \left(\boldsymbol{X}_{i t}^{\prime} \boldsymbol{\delta}_{1}\right)}{1+b_{i} \exp \left(\boldsymbol{X}_{i t}^{\prime} \boldsymbol{\delta}_{1}\right)},
\end{aligned}
$$

where $b_{i} \equiv \exp \left(\alpha_{i}^{L}\right)$ is a block group-specific coefficient, $\mu_{t}^{L}$ is the year fixed effect, while $\boldsymbol{X}$ and $\boldsymbol{\delta}_{1}$ again denote the vectors of time variables and observed regressors and their respective coefficients. As discussed in Section 4.2, the presence of $N$ block group-specific coefficients can be problematic in a nonlinear setting, unless $\hat{\boldsymbol{\delta}}_{\mathbf{1}}$ can be derived independently of $\hat{b}_{i}$. For the case of logit with fixed effects, early work by Rasch $(1960,1961)$, Andersen (1972), and Chamberlain (1980) established that model parameters can be estimated using a conditional maximum likelihood estimator (CMLE). In particular, this estimator uses the sum of outcomes within each group $i$ as a minimal sufficient statistic for $i$ 's group-specific parameter. As a result, groups with all equal outcomes (all positive or all zeros) are not used in the estimation. Using $\ell_{i}^{L}$ to denote the conditional loglikelihood for all observations in block group $i$, it can be shown that

$$
\ell_{i}^{L}\left(b_{i}, \boldsymbol{\delta}_{1} \mid \sum_{t=1}^{T} \iota_{i t}\right)=\ell_{i}^{L}\left(\boldsymbol{\delta}_{1} \mid \sum_{t=1}^{T} \iota_{i t}\right),
$$

that is, the conditional log-likelihood does not depend on the fixed effects parameter $b_{i}$. The remaining parameters are then estimated by maximizing $\sum_{i=1}^{N} \ell_{i}^{L}$. The conditional maximum likelihood estimator for this model, $\hat{\boldsymbol{\delta}}_{1, \mathrm{CMLE}}$, is consistent under mild restrictions on the rate at which the sequence of $b_{i}$ 's grows to infinity (Andersen (1970), Chamberlain (1980)). ${ }^{10}$

\footnotetext{
${ }^{10}$ However, as noted by Greene and Hensher (2010), the conditional likelihood of the logit is based on a restricted dataset that excludes all groups with equal outcomes over time, as well as all group-specific pa-
} 
Truncated Poisson The truncated Poisson model is estimated using only observations for which $Y_{i t}>0$. Allowing for unobserved block group heterogeneity, the truncated Poisson parameter $\lambda_{i t}$ for each one of these observations can be expressed as follows:

$$
\lambda_{i t}=\exp \left(\alpha_{i}^{P}+\boldsymbol{w}_{i t}^{\prime} \boldsymbol{\theta}_{2}+\mu_{t}^{P}\right) \equiv c_{i} \exp \left(\boldsymbol{X}_{i t}^{\prime} \boldsymbol{\delta}_{2}\right) \equiv c_{i} \beta_{i t},
$$

with year fixed effects represented by $\mu_{t}^{P}, c_{i} \equiv \exp \left(\alpha_{i}^{P}\right), \boldsymbol{\delta}_{2}$, as before, denoting a vector of parameters for the time variables and all remaining observed regressors, and $\beta_{i t} \equiv$ $\exp \left(\boldsymbol{X}_{i t}^{\prime} \boldsymbol{\delta}_{2}\right)$. Unlike the fixed effects Poisson model, estimating a zero-truncated Poisson with individual fixed effects through maximum likelihood does not allow for $\boldsymbol{\delta}_{2}$ to be estimated independently of the fixed effects coefficients. Therefore, MLE is inconsistent in this specification.

As shown by Majo and van Soest (2011), conditional maximum likelihood can be employed in this setting, in a similar fashion to the fixed effects logit model, which eliminates the fixed effects parameters from the estimation. Majo and van Soest (2011) demonstrated this method for a two-period panel dataset. In what follows, we generalize their procedure to any panel with an arbitrary number of longitudinal observations.

Let $\mathcal{T}_{i} \subseteq\{1, \ldots, T\}$ be the subset of periods with $Y_{i t}>0$ and let $Y_{i}^{*}=\left\{Y_{i t}: t \in \mathcal{T}_{i}\right\}$. Also, let $\boldsymbol{X}_{i}=\left\{\boldsymbol{X}_{i t}: t \in \mathcal{T}_{i}\right\}$ denote the matrix of regressors and $\boldsymbol{\lambda}_{i}=\left\{\lambda_{i t}: t \in \mathcal{T}_{i}\right\}$ be the vector of corresponding truncated Poisson parameters. Define the statistic $n_{i}=\sum_{t \in \mathcal{T}_{i}} Y_{i t}=$ $\sum_{t=1}^{T} Y_{i t}$. Finally, let $H_{i}\left(n_{i}\right)$ be the set of all possible histories of strictly positive natural numbers $\boldsymbol{d}_{i}=\left\{d_{i t} \in \mathbb{N}_{+}: t \in \mathcal{T}_{i}\right\}$ such that $\sum_{t \in \mathcal{T}_{i}} d_{i t}=n_{i}$. Then we have that

$$
\begin{aligned}
\operatorname{Pr}\left(\boldsymbol{Y}_{i}^{*}=\boldsymbol{y}_{i} \mid \boldsymbol{X}_{i}, n_{i}, c_{i}, \boldsymbol{\delta}_{2}\right) & =\frac{\operatorname{Pr}\left(\boldsymbol{Y}_{i}^{*}=\boldsymbol{y}_{i} \mid \boldsymbol{X}_{i}, c_{i}, \boldsymbol{\delta}_{2}\right)}{\operatorname{Pr}\left(\sum_{t \in \mathcal{T}_{i}} Y_{i t}=n_{i} \mid \boldsymbol{X}_{i}, c_{i}, \boldsymbol{\delta}_{2}\right)} \\
& =\frac{\prod_{t \in \mathcal{T}_{i}} \frac{\lambda_{i t}^{y_{i t}}}{\sum_{i t} !\left(\exp \left(\lambda_{i t}\right)-1\right)}}{\sum_{\boldsymbol{d}_{i} \in H_{i}\left(n_{i}\right)}\left[\prod_{t \in \mathcal{T}_{i}} \frac{\lambda_{i t}^{d_{i t}}}{d_{i t} !\left(\exp \left(\lambda_{i t}\right)-1\right)}\right]} \\
& =\frac{1}{h_{i}\left(\boldsymbol{\lambda}_{i}\right)} \prod_{t \in \mathcal{T}_{i}} \frac{n_{i} !}{y_{i t} !} \lambda_{i t}^{y_{i t}},
\end{aligned}
$$

where $h_{i}\left(\boldsymbol{\lambda}_{i}\right) \equiv \sum_{\boldsymbol{d}_{i} \in H_{i}\left(n_{i}\right)} \prod_{t \in \mathcal{T}_{i}} \lambda_{i t}^{d_{i t}}$. Since $\lambda_{i t}=c_{i} \beta_{i t}$, it is easy to show that $h_{i}\left(\boldsymbol{\lambda}_{i}\right)=$ $h_{i}\left(c_{i} \boldsymbol{\beta}_{i}\right)=c_{i}^{n_{i}} h_{i}\left(\boldsymbol{\beta}_{i}\right)$, where $\boldsymbol{\beta}_{i}=\left\{\beta_{i t}: t \in \mathcal{T}_{i}\right\}$. In other words, the function $h_{i}(\cdot)$ is homogeneous of degree $n_{i}$ in $\boldsymbol{\beta}_{i}$. So, from (14),

$$
\frac{1}{h_{i}\left(\boldsymbol{\lambda}_{i}\right)} \prod_{t \in \mathcal{T}_{i}} \frac{n_{i} !}{y_{i t} !} \lambda_{i t}^{y_{i t}}=\frac{1}{c_{i}^{n_{i}} h_{i}\left(\boldsymbol{\beta}_{i}\right)} \prod_{t \in \mathcal{T}_{i}} \frac{n_{i} !}{y_{i t} !} c_{i}^{y_{i t}} \beta_{i t}^{y_{i t}}=\frac{1}{h_{i}\left(\boldsymbol{\beta}_{i}\right)} \prod_{t \in \mathcal{T}_{i}} \frac{n_{i} !}{y_{i t} !} \beta_{i t}^{y_{i t}},
$$

rameters, and is therefore not comparable to the unrestricted likelihood of alternative model specifications. This prevents the implementation of model selection tests based on likelihood ratio statistics, including selection tests among nonnested models, such as the Vuong test (Vuong (1989)) and its extensions (e.g., Chen, Hong, and Shum (2007)). 
that is, upon conditioning on $\sum_{t=1}^{T} Y_{i t}$, the truncated Poisson distribution no longer depends on the nuisance parameter $c_{i}$ but still depends on the parameters of interest $\boldsymbol{\delta}_{2}$, as long as $\widetilde{\mathcal{T}}_{i}$ contains at least two periods and the explanatory variables $\boldsymbol{X}_{i t}$ are not constant over $\tilde{\mathcal{T}}_{i}$. The conditional log-likelihood then takes the following form:

$$
\begin{aligned}
L\left(\boldsymbol{\delta}_{2}\right) & =\sum_{i=1}^{N} \ell_{i}^{P}\left(\boldsymbol{\delta}_{2} \mid \sum_{t=1}^{T} Y_{i t}\right) \\
& =\sum_{i=1}^{N}\left\{\log \left[\left(\sum_{t \in \mathcal{T}_{i}} Y_{i t}\right) !\right]-\sum_{t \in \mathcal{T}_{i}} \log \left[Y_{i t} !\right]+\sum_{t \in \mathcal{T}_{i}} Y_{i t} \log \left(\beta_{i t}\right)-\log \left(h_{i}\right)\right\},
\end{aligned}
$$

where $\ell_{i}^{P}$ is the conditional log-likelihood for all observations from block group $i$ with $Y_{i t}>0$.

This procedure is rather general and can be applied to an arbitrarily large number of longitudinal panel observations and any number of model parameters. The parameter estimator of this fixed effects truncated Poisson model is obtained as $\hat{\boldsymbol{\delta}}_{2, \mathrm{CMLE}}=$ $\arg \max _{\boldsymbol{\delta}_{2}} L\left(\boldsymbol{\delta}_{2}\right)$. Under strict exogeneity of the regressors $\boldsymbol{X}, \hat{\boldsymbol{\delta}}_{2, \text { CMLE }}$ can be shown to be a consistent estimator of $\boldsymbol{\delta}_{2}$ (See Appendix A).

\subsection{Endogeneity}

Both the logit and truncated Poisson conditional likelihood estimators, discussed in Section 5.2, are consistent, provided that the respective models are specified appropriately. However, this would no longer be the case with endogeneity of price. We thus extend the hurdle model further in order to accommodate the implementation of a suitable instrumental variable procedure. Once again, we address the problem separately in the logit and truncated Poisson portions of the model.

Logit In the discrete choice literature, a number of methods have been developed to tackle endogeneity in demand settings. These include the product-market control (and instrumental variable) approach of Berry, Levinsohn, and Pakes (1995), a simulated maximum likelihood approach developed by Gupta and Park (2009), and Bayesian methods employed by Yang, Chen, and Allenby (2003) and Jiang, Manchanda, and Rossi (2009). More recently, Petrin and Train (2010) proposed a control function approach that is arguably easier to estimate and more flexible than the above methods, as it does not require invoking equilibrium or imposing strict distributional assumptions for the identification of demand parameters.

As in Section 4.2, dropping subscripts for simplicity, let $\boldsymbol{W}=\left(p, \boldsymbol{Z}_{1}\right)^{\prime}$ and $\boldsymbol{Z}_{1} \subset \boldsymbol{Z}$, where $\boldsymbol{Z}$ is a vector of exogenous variables. Also, let $\boldsymbol{\Theta}_{1}=\left(\gamma_{1}, \boldsymbol{\Gamma}_{1}\right)^{\prime}$. Suppose the purchase of any positive number of PV systems in a given block group generates utility $u$, given by

$$
u=\gamma_{1} p+\boldsymbol{Z}_{1}^{\prime} \boldsymbol{\Gamma}_{1}+\zeta_{1},
$$

where $\zeta_{1}$ denotes an idiosyncratic term that is correlated with price $p$. As in Section 4.2, let

$$
p=\boldsymbol{Z}^{\prime} \Pi+r .
$$


Since $\zeta_{1}$ is correlated with $p$ but not with $Z$, there exists some function $C F\left(r, \rho_{1}\right)$, where $\rho_{1}$ is a parameter, such that $\zeta_{1}=C F\left(r, \rho_{1}\right)+\tilde{\zeta}_{1}$ and $\tilde{\zeta}_{1}$ is uncorrelated with $p$. We can then rewrite (16) as

$$
u=\gamma_{1} p+\boldsymbol{Z}_{1}^{\prime} \boldsymbol{\Gamma}_{1}+C F\left(r, \rho_{1}\right)+\tilde{\zeta}_{1}=\boldsymbol{W}^{\prime} \boldsymbol{\Theta}_{1}+C F\left(r, \rho_{1}\right)+\tilde{\zeta}_{1} .
$$

Therefore, if we estimate our model including the control function $C F\left(r, \rho_{1}\right)$ with valid instruments, we can consistently estimate $\boldsymbol{\Theta}_{1}$.

Petrin and Train (2010) suggested several simplifying assumptions. First, as an alternative to specifying a joint distribution for both error terms in (16) and (17), one could enter $r$ flexibly in the utility and then choose a distributional assumption for $\tilde{\zeta}_{1}$. Second, the control function can be approximated as a linear function. Accordingly, we specify $C F\left(r, \rho_{1}\right)$ as $\rho_{1} r$ in (18) and assume that $\tilde{\zeta}_{1}$ is distributed i.i.d. type I extreme value. ${ }^{11}$ The probability of $Y>0$ is now given by

$$
\operatorname{Pr}\left[Y_{i t}>0 \mid \boldsymbol{W}_{i t}, \boldsymbol{\Theta}_{1}\right]=\frac{b_{i} \exp \left(\boldsymbol{X}_{i t}^{\prime} \boldsymbol{\delta}_{1}+\rho_{1} r\right)}{1+b_{i} \exp \left(\boldsymbol{X}_{i t}^{\prime} \boldsymbol{\delta}_{1}+\rho_{1} r\right)} .
$$

As in our earlier discussion from Section 4.2, this CF specification implies a twostage estimation procedure. In the first stage, we run a linear regression of price on all excluded and included instruments. The residuals from this stage are then included as a covariate in the second-stage estimation, which, following the discussion from Section 5.2, is carried out using conditional maximum likelihood in order to eliminate the nuisance parameters. Finally, we bootstrap the standard errors to ensure that our inference accounts for both stages.

Truncated Poisson To our knowledge, we are the first to address endogeneity of one or more of the regressors in a fixed effects truncated Poisson model. In what follows, we develop a generalized method of moments (GMM) procedure for the consistent estimation of the vector of truncated Poisson slope parameters $\boldsymbol{\delta}_{2}$ in cases where $\boldsymbol{X}$ is no longer strictly exogenous. $^{12}$

Recall that the function $h_{i}\left(\boldsymbol{\beta}_{i}\right)$, described in Section 5.2, is homogeneous of degree $n_{i}$ in $\boldsymbol{\beta}_{i}$. This implies that $\sum_{t \in \mathcal{T}_{i}} \frac{\partial h_{i}(\cdot)}{\partial \beta_{i t}} \beta_{i t}=n_{i} h_{i}(\cdot)$, or $\sum_{t \in \mathcal{T}_{i}} \frac{\partial h_{i}(\cdot)}{\partial \beta_{i t}} \frac{\beta_{i t}}{h_{i}(\cdot)}=n_{i}$. For convenience, we now define a nonlinear function $\phi_{i t}$ of all regressors and slope parameters in the truncated Poisson model:

$$
\phi_{i t}\left(\boldsymbol{X}_{i}, \boldsymbol{\delta}_{2}\right) \equiv \frac{\frac{\partial h_{i}\left(\boldsymbol{\beta}_{i}\right)}{\partial \beta_{i t}} \beta_{i t}}{h_{i}\left(\boldsymbol{\beta}_{i}\right)}
$$

\footnotetext{
${ }^{11}$ Alternatively, $C F\left(r, \rho_{1}\right)$ can be specified as a quadratic function (e.g., Olley and Pakes (1996)). We also reestimated our model using a quadratic control function and found the results to be quite robust.

${ }^{12}$ Alternatively, endogeneity in the truncated Poisson model could be addressed through a control function approach. However, unlike the GMM approach, this would require further assumptions about the functional form and distribution of the model's error term, which would be complicated by the nonlinearity in $\lambda$.
} 
By definition, it follows that $\sum_{t \in \mathcal{T}_{i}} \phi_{i t}=\sum_{t \in \mathcal{T}_{i}} Y_{i t}$ since both are equal to $n_{i}$. Using this equivalence and the Weak Law of Large Numbers, $\frac{1}{N} \sum_{i=1}^{N} \frac{1}{T_{i}^{*}} \sum_{t \in \mathcal{T}_{i}} \phi_{i t}=\frac{1}{N} \sum_{i=1}^{N} \frac{1}{T_{i}^{*}} \times$ $\sum_{t \in \mathcal{T}_{i}} Y_{i t} \stackrel{p}{\rightarrow} \mathrm{E}^{P}\left[Y_{i t}\right]$, where $T_{i}^{*}=\max \left\{t: Y_{i t}>0\right\}$. Hence, in our context $\phi_{i t}$ can be interpreted asymptotically as the predicted number of installations in block group $i$ at time $t$, conditional on the occurrence of a positive number of installations. Note that this interpretation follows directly from the functional form of $\phi_{i t}$ and does not require any assumptions about the exogeneity of $\boldsymbol{X}_{i}$.

Based on this interpretation, we proceed to construct the following model of the zero-truncated demand for solar PV:

$$
Y_{i t}=\phi_{i t}\left(\boldsymbol{X}_{i}, \boldsymbol{\delta}_{2}\right)+\xi_{i t},
$$

where $\xi_{i t}$ is the econometrician's error, which represents block group and year-specific idiosyncratic shocks that influence the number of adoptions. We now use this model to derive moment conditions for the estimation of $\boldsymbol{\delta}_{2}$, both in the absence and in the presence of endogenous regressors.

Let $\boldsymbol{\xi}_{i}=\left(\xi_{i 1}, \ldots, \xi_{i T^{*}}\right)^{\prime}$. If $\boldsymbol{X}$ is strictly exogenous in the demand model, the resultant orthogonality with the error term $\boldsymbol{\xi}_{i}$ provides a moment condition $\mathrm{E}\left[\boldsymbol{X}_{i}^{\prime} \boldsymbol{\xi}_{i}\right]=\mathbf{0}$, with the sample analog of this condition leading to a GMM estimator of $\boldsymbol{\delta}_{2}$. As demonstrated in Appendix B, this GMM estimator turns out to be equivalent to $\hat{\boldsymbol{\delta}}_{2, \mathrm{CMLE}}$, which was shown in Appendix A to be a consistent estimator of $\boldsymbol{\delta}_{2}$ under strict exogeneity of all regressors.

However, with one or more endogenous regressors in the model, $\mathrm{E}\left[\boldsymbol{X}_{i}^{\prime} \boldsymbol{\xi}_{i}\right]=\mathbf{0}$ no longer holds. In that case, a vector $\boldsymbol{Z}$, comprised only of variables that are exogenous in the model, would be orthogonal to the error term in (19), that is,

$$
\mathrm{E}\left[\boldsymbol{Z}_{i}^{\prime} \boldsymbol{\xi}_{i}\right]=\mathbf{0}
$$

where $\boldsymbol{Z}_{i}=\left(\boldsymbol{Z}_{i 1}, \ldots, \boldsymbol{Z}_{i T^{*}}\right)^{\prime}$. Then, if $\boldsymbol{\delta}_{2}$ is a $P$-dimensional vector, we can use the sample analog of (20) in order to estimate $\boldsymbol{\delta}_{2}$ through a GMM estimator, as long as there are a total of at least $P$ exogenous variables in $\boldsymbol{Z}$. Suppose $\boldsymbol{Z}_{i t} \in \mathcal{Z} \subset \mathbb{R}^{Q}$, where $Q>P$, and let $\psi\left(\boldsymbol{Z}_{i}, \boldsymbol{\delta}_{2}\right)=\boldsymbol{Z}_{i}^{\prime} \boldsymbol{\xi}_{i}$. Then

$$
\hat{\boldsymbol{\delta}}_{2, \mathrm{GMM}}=\arg \max _{\boldsymbol{\delta}_{2}}\left[\frac{1}{N} \sum_{i=1}^{N} \psi\left(\boldsymbol{Z}_{i}, \boldsymbol{\delta}_{2}\right)\right]^{\prime} \hat{\Xi}\left[\frac{1}{N} \sum_{i=1}^{N} \psi\left(\boldsymbol{Z}_{i}, \boldsymbol{\delta}_{2}\right)\right],
$$

where $\hat{\Xi}$ is an optimal weighting matrix. In Appendix A, we demonstrate that under the standard GMM assumptions $\hat{\boldsymbol{\delta}}_{2, \mathrm{GMM}}$ is a consistent estimator of $\boldsymbol{\delta}_{2}$.

\subsection{Deriving the price elasticity}

The estimators derived in Sections 5.2 and 5.3 do not allow us to estimate the fixed effects parameters in the model. As a result, we are not able to recover the predicted conditional expectations or calculate the exact marginal effects, needed for the derivation 
of price elasticity. ${ }^{13}$ Instead, we develop, in the spirit of Kitazawa (2012), a procedure for obtaining average elasticity estimates that are shown to converge to the true average elasticity values as $N \rightarrow \infty$.

Logit The average price elasticity in the logit model is given by $\eta^{L}=\left(1-\operatorname{Pr}\left[Y_{i t}>\right.\right.$ 0]) $\gamma_{1} \mathrm{E}\left[p_{i t}\right]$, where $\gamma_{1}$ is the coefficient on price. The following proposition derives an expression for the consistent estimator of $\eta^{L}$.

Proposition 1. Let $\hat{\eta}^{L}=(1-\bar{\imath}) \hat{\gamma}_{1} \bar{p}$, where $\bar{\imath}=\frac{1}{N T} \sum_{i=1}^{N} \sum_{t=1}^{T} \iota_{i t}, \bar{p}=\frac{1}{N T} \sum_{i=1}^{N} \sum_{t=1}^{T} p_{i t}$, and $\hat{\gamma}_{1} \stackrel{p}{\rightarrow} \gamma_{1}$. Then $\hat{\eta}^{L} \stackrel{p}{\rightarrow} \eta^{L}$.

Proof. By the Weak Law of Large Numbers (WLLN), $\iota \stackrel{p}{\rightarrow} \operatorname{Pr}\left[Y_{i t}>0\right]$ and $\bar{p} \stackrel{p}{\rightarrow} \mathrm{E}\left[p_{i t}\right]$. Then, since $\hat{\gamma}_{1} \stackrel{p}{\rightarrow} \gamma_{1}$, by the Continuous Mapping Theorem (CMT), $\hat{\eta}^{L}=(1-\bar{\imath}) \hat{\gamma}_{1} \vec{p} \stackrel{p}{\rightarrow}$ $\left(1-\operatorname{Pr}\left[Y_{i t}>0\right]\right) \gamma_{1} \mathrm{E}\left[p_{i t}\right]=\eta^{L}$.

This is intuitive. Note that $\operatorname{Pr}\left[Y_{i t}>0 \mid \boldsymbol{W}_{i t}, \boldsymbol{\Theta}_{1}\right]=\frac{b_{i} \exp \left(\boldsymbol{X}_{i \boldsymbol{t}}^{\prime} \boldsymbol{\delta}_{1}\right)}{1+b_{i} \exp \left(\boldsymbol{X}_{i t}^{\prime} \boldsymbol{\delta}_{1}\right)}$. Since we do not have an estimate of $b_{i}$, we cannot use the post-estimation predicted probabilities to calculate $\eta^{L}$. However, asymptotically, the sample averages $\bar{\imath}$ and $\bar{p}$ converge in probability to $\operatorname{Pr}\left[Y_{i t}>0\right]$ and $\mathrm{E}\left[p_{i t}\right]$, respectively. Hence, we can use these averages, together with the consistent logit CF estimate of $\gamma_{1}$, to obtain a consistent estimator of $\eta^{L}$.

Truncated Poisson Similarly, we derive an estimator for the average elasticity in the zero-truncated Poisson portion of the hurdle model. First, since $\lambda_{i t}=c_{i} \exp \left(\boldsymbol{X}_{i t}^{\prime} \boldsymbol{\delta}_{2}\right)$ and we do not estimate $c_{i}$, we proceed to express $\lambda_{i t}$ as a function of $\mathrm{E}^{P}\left[Y_{i t}\right]$. Note that

$$
\mathrm{E}^{P}\left[Y_{i t}\right]=\frac{\lambda_{i t}}{1-\exp \left(-\lambda_{i t}\right)} \equiv m\left(\lambda_{i t}\right)
$$

Then $\lambda_{i t}=m^{-1}\left(\mathrm{E}^{P}\left[Y_{i t}\right]\right)$. As shown in Appendix C, $m(\cdot)$ is a monotonic function over the relevant range of $\lambda_{i t}$ values in this model, implying that $m^{-1}(\cdot)$ is a one-to-one mapping from $\mathrm{E}^{P}\left[Y_{i t}\right]$ to $\lambda_{i t}$.

Next, it can be shown that the average price elasticity is given by

$$
\eta^{P}=\left(1+\lambda_{i t}-\mathrm{E}^{P}\left[Y_{i t}\right]\right) \gamma_{2} \mathrm{E}^{P}\left[p_{i t}\right]=\left(1+m^{-1}\left(\mathrm{E}^{P}\left[Y_{i t}\right]\right)-\mathrm{E}^{P}\left[Y_{i t}\right]\right) \gamma_{2} \mathrm{E}^{P}\left[p_{i t}\right],
$$

where $\gamma_{2}$ is the coefficient on price in the truncated Poisson model. This suggests a straightforward estimator of $\eta^{P}$, presented in the following proposition.

Proposition 2. Let $\hat{\eta}^{P}=\left(1+m^{-1}\left(\bar{Y}^{P}\right)-\bar{Y}^{P}\right) \hat{\gamma}_{2} \bar{p}^{P}$, where $\bar{Y}^{P}=\frac{1}{N} \sum_{i=1}^{N} \frac{1}{T_{i}^{*}} \sum_{t \in \mathcal{T}_{i}} Y_{i t}$, $\bar{p}^{P}=\frac{1}{N} \sum_{i=1}^{N} \frac{1}{T_{i}^{*}} \sum_{t \in \mathcal{T}_{i}} p_{i t}$, and $\hat{\gamma}_{2} \stackrel{p}{\rightarrow} \gamma_{2}$. Then $\hat{\eta}^{P} \stackrel{p}{\rightarrow} \eta^{P}$.

Proof. By WLLN, $\bar{Y}^{P} \stackrel{p}{\rightarrow} \mathrm{E}^{P}\left[Y_{i t}\right]$ and $\bar{p}^{P} \stackrel{p}{\rightarrow} \mathrm{E}^{P}\left[p_{i t}\right]$. By CMT, $m^{-1}\left(\bar{Y}^{P}\right) \stackrel{p}{\rightarrow} m^{-1}\left(\mathrm{E}^{P}\left[Y_{i t}\right]\right)$. Since $\hat{\gamma}_{2} \stackrel{p}{\rightarrow} \gamma_{2}, \hat{\eta}^{P}=\left(1+m^{-1}\left(\bar{Y}^{P}\right)-\bar{Y}^{P}\right) \hat{\gamma}_{2} \bar{p}^{P} \stackrel{p}{\rightarrow}\left(1+m^{-1}\left(\mathrm{E}^{P}\left[Y_{i t}\right]\right)-\mathrm{E}^{P}\left[Y_{i t}\right]\right) \gamma_{2} \mathrm{E}^{P}\left[p_{i t}\right]=$ $\eta^{P}$, by CMT.

\footnotetext{
${ }^{13}$ Furthermore, this implies that model selection tests based on conditional expectations (e.g., Silva, Tenreyro, and Windmeijer (2015)) cannot be implemented.
} 
TABLE 5. Monte Carlo simulation results.

\begin{tabular}{|c|c|c|c|c|c|c|c|}
\hline \multirow[b]{3}{*}{ Specification } & \multicolumn{4}{|c|}{ Parameters } & \multicolumn{3}{|c|}{ Elasticity } \\
\hline & \multirow{2}{*}{$\begin{array}{c}\text { True } \\
\text { Value }\end{array}$} & \multicolumn{3}{|c|}{ Estimated } & \multirow{2}{*}{$\begin{array}{c}\text { True } \\
\text { Value }\end{array}$} & \multicolumn{2}{|c|}{ Implied } \\
\hline & & Mean & Bias & MSE & & Value & Bias \\
\hline Logit CF & $\delta_{1}=-0.1$ & -0.0961 & 0.0039 & 0.0003 & $\eta_{1}=-0.0767$ & -0.0780 & -0.0013 \\
\hline Tr. Poisson GMM & $\delta_{2}=-0.1$ & -0.0999 & 0.0001 & 0.0001 & $\eta_{2}=-0.1716$ & -0.1712 & 0.0004 \\
\hline Poisson hurdle & $\mathrm{n} / \mathrm{a}$ & $\mathrm{n} / \mathrm{a}$ & $\mathrm{n} / \mathrm{a}$ & $\mathrm{n} / \mathrm{a}$ & $\eta=-0.2483$ & -0.2493 & -0.0010 \\
\hline Linear 2SLS & $\mathrm{n} / \mathrm{a}$ & -0.2257 & $\mathrm{n} / \mathrm{a}$ & $\mathrm{n} / \mathrm{a}$ & $\eta=-0.2483$ & -0.2654 & -0.0171 \\
\hline Poisson CF & $\mathrm{n} / \mathrm{a}$ & -0.1103 & $\mathrm{n} / \mathrm{a}$ & $\mathrm{n} / \mathrm{a}$ & $\eta=-0.2483$ & -0.2659 & -0.0176 \\
\hline
\end{tabular}

Note: See Online Appendix B.2 in the Supplemental Material (Gillingham and Tsvetanov (2019)) for details about construction of the simulated data. Output is based on 5000 replications. Sample means and parameter values, averaged over the 5000 replications, are used to compute elasticity under each specification. Elasticity values in the hurdle model are calculated using the formulas in Section 5.4. The elasticity in the linear model is derived from $\hat{\eta}=\frac{\hat{\delta} \bar{w}}{\bar{y}}$. The elasticity in the Poisson model is derived from $\hat{\eta}=\hat{\delta} \bar{w}$.

Thus, $\eta^{P}$ can be consistently estimated using the mean values for installations and prices in the truncated sample, along with the GMM estimate $\hat{\gamma}_{2}$.

\subsection{Monte Carlo simulations}

While we have already proven the consistency of our estimator, we conduct a set of Monte Carlo simulations to evaluate its performance. In short, we simulate data from our data generating process and then apply our estimator and alternative estimators to the simulated data. We use a simple panel data framework, in which the outcome count variable is determined by a set of unobserved time-invariant and time-varying crosssection-specific factors and a single endogenous regressor. The model, data generation process, and parameter values used in these simulations are described in Online Appendix B.2 in the Supplemental Material (Gillingham and Tsvetanov (2019)).

Our results are encouraging. Table 5 shows the results from one representative simulation. The bias on each of the parameters of interest using the logit CF and truncated Poisson GMM is small: $3 \%$ for the logit CF and $0.2 \%$ for the truncated Poisson. Converting this to an elasticity, we find that our estimated (combined) elasticity is within $1.2 \%$ of true elasticity value. Compared to the results obtained using linear two-stage least squares (2SLS) and Poisson CF approaches, we find that our estimated elasticity is much closer to the true value. We repeat this procedure with several different sets of parameter values and find similar results. ${ }^{14}$

\footnotetext{
${ }^{14}$ We also run another set of Monte Carlo simulations (described in Online Appendix B.3 in the Supplemental Material (Gillingham and Tsvetanov (2019))), which shows that even in the case where the true data generation process is Poisson with fixed effects and an endogenous regressor (i.e., it does not have excess zeros), the hurdle model still performs very well in recovering the true values.
} 


\section{Results}

\subsection{Primary results}

Our identification strategy relies on the validity of our instruments. As described earlier, we use two marginal cost shifters as instruments for the post-incentive price: average incentive levels in $\$ / \mathrm{W}$ for the first $5 \mathrm{~kW}$ of installed capacity in each block group-year and county-year average roofer wages. Incentives are given directly to installers in CT, so they act as a shifter of the firm marginal cost. Due to the declining incentives and time lag between the submission and approval of contract applications, there is both temporal and cross-sectional variation in incentive levels. ${ }^{15}$ County-year average roofer wages are used as a proxy for PV system installer labor costs, and are a valid shifter after controlling for income. ${ }^{16}$ Online Appendix C contains the results of the first-stage regression, demonstrating that we do not have to worry about weak instruments.

Table 6 presents the results from estimating a linear model, Poisson model, and Poisson hurdle model with instruments for price. ${ }^{17}$ Our preferred specification is the instrumental variables hurdle model, consisting of a logit regression estimated with a control function approach in column (3) and a trucated Poisson estimated by GMM in column (4). All columns include block group fixed effects and year dummies. Standard errors are clustered at the town level. At the bottom of the table, we present estimates of the price elasticity of demand for each specification.

We are most interested in the statistical and economic significance of the price coefficient. We find negative and statistically significant coefficients on the price variable in all model specifications. Rather than interpreting the coefficient directly, we find it more instructive to consider the price elasticity implied by the coefficient taken at the mean of our sample. ${ }^{18}$ Estimating the model using a Poisson specification implies a considerably higher (in absolute value) price elasticity relative to the linear specification. A linear 2SLS regression yields a price elasticity of -0.62 . Fitting a Poisson model generates an elasticity coefficient that is almost twice as high. However, both of these empirical specifications are unsuited for our data with excess zeros, as discussed in Section 4.

As shown earlier, the total price elasticity of the hurdle model, which is our preferred specification, is the sum of the elasticities from the logit and truncated Poisson. Summing the price elasticity estimates in columns (3) and (4) shows that the hurdle model

\footnotetext{
${ }^{15}$ The time lag provides cross-sectional variation because the incentives granted are based on the approval date of the contract. Consumers are assumed to have rational expectations about what the awarded incentive will be at the time of approval.

${ }^{16}$ While over-identification tests are never definitive, we use a Hansen's J overidentification test to examine the validity of the instruments in the truncated Poisson GMM specification of our hurdle model. Comfortingly, we find that we fail to reject the null of valid instruments, with a Chi-squared test statistic of 0.47 and a $p$-value of 0.49 . We find similar results for other specifications.

${ }^{17}$ For completeness, Online Appendix D in the Supplemental Material (Gillingham and Tsvetanov (2019)) also presents output from the same model specification without the use of instrumental variables. We view these results with great caution as the coefficients are most likely biased due to the endogeneity of price.

${ }^{18}$ The price elasticity in the linear model is estimated as $\eta=\frac{\hat{\gamma} \bar{p}}{\bar{Y}}$, where $\hat{\gamma}$ is the two-stage least squares (2SLS) estimate of the price coefficient and $\bar{p}$ and $\bar{Y}$ are the sample means for price and number of installations. The price elasticity in the Poisson model is estimated as $\eta=\hat{\gamma} \bar{p}$, where $\hat{\gamma}$ is the Poisson CF estimate of the price coefficient.
} 
Table 6. Primary estimation results.

\begin{tabular}{|c|c|c|c|c|}
\hline \multirow[b]{3}{*}{ Variable } & \multirow[b]{2}{*}{ Linear } & \multirow[b]{2}{*}{ Poisson } & \multicolumn{2}{|c|}{ Hurdle } \\
\hline & & & Logit & Trun. Poisson \\
\hline & $\begin{array}{l}2 S L S^{i} \\
(1)\end{array}$ & $\begin{array}{c}\text { CFii } \\
(2)\end{array}$ & $\begin{array}{l}\mathrm{CF}^{\mathrm{ii}} \\
(3)\end{array}$ & $\begin{array}{c}\mathrm{GMM}^{\mathrm{i}} \\
(4)\end{array}$ \\
\hline Price & $\begin{array}{c}-0.079^{* * *} \\
(0.0292)\end{array}$ & $\begin{array}{c}-0.286^{* * *} \\
(0.0982)\end{array}$ & $\begin{array}{c}-0.201^{* *} \\
(0.0999)\end{array}$ & $\begin{array}{c}-0.292^{* *} \\
(0.132)\end{array}$ \\
\hline Solarize & $\begin{array}{c}0.929^{* * *} \\
(0.242)\end{array}$ & $\begin{array}{c}0.913^{* * *} \\
(0.15)\end{array}$ & $\begin{array}{c}0.863^{* * *} \\
(0.204)\end{array}$ & $\begin{array}{c}0.877^{* * *} \\
(0.161)\end{array}$ \\
\hline Pop. density & $\begin{array}{l}-5.6 \times 10^{-6} \\
\left(9.4 \times 10^{-6}\right)\end{array}$ & $\begin{array}{c}-0.0002^{* * *} \\
(0.00007)\end{array}$ & $\begin{array}{c}-0.0002^{* *} \\
(0.00009)\end{array}$ & $\begin{array}{c}0.0004 \\
(0.0005)\end{array}$ \\
\hline Income & $\begin{array}{c}0.0008 \\
(0.00077)\end{array}$ & $\begin{array}{c}0.0004 \\
(0.00154)\end{array}$ & $\begin{array}{c}-0.0014 \\
(0.00152)\end{array}$ & $\begin{array}{c}0.0013 \\
(0.00267)\end{array}$ \\
\hline Age & $\begin{array}{c}-0.003 \\
(0.0026)\end{array}$ & $\begin{array}{c}-0.012^{* *} \\
(0.0047)\end{array}$ & $\begin{array}{c}-0.0096^{*} \\
(0.0053)\end{array}$ & $\begin{array}{l}-0.008 \\
(0.012)\end{array}$ \\
\hline$\%$ (some) college & $\begin{array}{c}0.0003 \\
(0.001)\end{array}$ & $\begin{array}{l}0.0002 \\
(0.003)\end{array}$ & $\begin{array}{c}0.002 \\
(0.004)\end{array}$ & $\begin{array}{c}0.005 \\
(0.007)\end{array}$ \\
\hline$\% \mathrm{grad} /$ prof degree & $\begin{array}{c}0.001 \\
-0.002\end{array}$ & $\begin{array}{c}-0.0003 \\
-0.004\end{array}$ & $\begin{array}{c}0.006 \\
-0.005\end{array}$ & $\begin{array}{l}-0.005 \\
(0.008)\end{array}$ \\
\hline$\%$ Republican & $\begin{array}{c}0.063^{* * *} \\
(0.024)\end{array}$ & $\begin{array}{c}0.077^{*} \\
(0.040)\end{array}$ & $\begin{array}{c}0.036 \\
(0.041)\end{array}$ & $\begin{array}{c}0.153^{* * *} \\
(0.059)\end{array}$ \\
\hline$\%$ Democrat & $\begin{array}{c}0.027^{* *} \\
(0.0126)\end{array}$ & $\begin{array}{c}0.041^{*} \\
(0.0222)\end{array}$ & $\begin{array}{c}0.011 \\
(0.0248)\end{array}$ & $\begin{array}{l}0.102^{* * *} \\
(0.0384)\end{array}$ \\
\hline BG FE & yes & yes & yes & yes \\
\hline Year Dummies & yes & yes & yes & yes \\
\hline Instruments & yes & yes & yes & yes \\
\hline Price elasticity ${ }^{\mathrm{iii}}$ & $\begin{array}{c}-0.621^{* * *} \\
(0.2301)\end{array}$ & $\begin{array}{c}-1.076^{* * *} \\
(0.3698)\end{array}$ & $\begin{array}{c}-0.528^{* *} \\
(0.2626)\end{array}$ & $\begin{array}{c}-0.123^{* *} \\
(0.0554)\end{array}$ \\
\hline Observations & 10,738 & 10,738 & 10,738 & 3238 \\
\hline
\end{tabular}

Note: Dependent variable is number of residential PV installations. Unit of observation is block group-year. BG FE refers to block group fixed effects. Year FE refers to year fixed effects. The instruments used for all IV specifications are the EPBB/HOPBI state financial incentives given to the installers and the county roofing contractor wage rate. $p<0.1\left({ }^{*}\right), p<0.05\left({ }^{* *}\right), p<0.01$ $(* * *)$.

${ }^{\mathrm{i}}$ Clustered standard errors at the town level in parentheses.

ii Block bootstrapped standard errors (100 replications), clustered at the town level, in parentheses.

iii Standard errors for the price elasticity obtained by the delta method.

implies a price elasticity of solar PV system demand of -0.65 . At the average system price and number of installations in our sample, this elasticity estimate suggests that a $\$ 1 / \mathrm{W}$ decrease in the installation price (well within the variation in our data) would lead to an increase in demand of approximately 0.083 additional PV systems in each block group during the respective year. In our data, there are 1534 block groups in any given year. Thus, a $\$ 1 / \mathrm{W}$ decrease in system price translates into 127 additional installations demanded statewide in that year.

The other coefficients are of less interest to us, but we are reassured to see that the signs are generally consistent and make sense. One of the more interesting of these is the coefficient on the indicator for whether a block group has a Solarize campaign, which 
is positive and highly statistically significant in all specifications. This is consistent with results in Gillingham and Bollinger (2017), which uses quasi-experimental and experimental approaches to find a large treatment effect of the Solarize program. The other statistically significant coefficients largely make sense in sign. Solar demand is higher in less densely populated areas and in areas with a younger population. Political views also appear to have a positive effect on the decision to adopt in the linear and truncated Poisson specifications. The general lack of statistical significance for the demographic and voting variables is likely attributable to the lack of sufficient time series variation in these variables.

\subsection{Robustness checks}

We perform several robustness checks, which are both reassuring and provide insight into the variation behind our results. Table 7 shows the estimated elasticities from each of these robustness checks and includes the elasticity estimates from our preferred specifications in columns (3) and (4) of Table 6 for comparison.

First, we are concerned that our results in the logit regression may be driven by the method we use to fill in missing price data in block group-years where no contracts were signed. We therefore reestimate the model using the highest, rather than average, recorded prices as proxies, preserving the order of our approach outlined in Section 3.1 (column (I)). We find that our logit CF estimates are only modestly affected by this change in the interpolation approach, a very reassuring result.

As an alternative, we also estimate a hedonic equilibrium price equation for each year using the subsample with positive installation counts at the block group level and

TAвLE 7. Elasticity values under different specifications.

\begin{tabular}{|c|c|c|c|c|c|c|}
\hline \multirow[b]{2}{*}{ Model Specification } & \multirow[b]{2}{*}{ Baseline } & \multicolumn{5}{|c|}{ Robustness Checks } \\
\hline & & I & II & III & IV & $\mathrm{V}$ \\
\hline Logit $C F^{i}$ & $\begin{array}{c}-0.528^{* *} \\
(0.2626)\end{array}$ & $\begin{array}{l}-0.478^{*} \\
(0.2778)\end{array}$ & $\begin{array}{l}-0.661^{*} \\
(0.3498)\end{array}$ & $\begin{array}{c}-0.530^{* *} \\
(0.2635)\end{array}$ & $\begin{array}{c}-0.521^{* *} \\
(0.2698)\end{array}$ & $\begin{array}{c}-0.543^{* *} \\
(0.2622)\end{array}$ \\
\hline Tr. Poisson GMM ${ }^{\mathrm{ii}}$ & $\begin{array}{c}-0.123^{* *} \\
(0.0554)\end{array}$ & $\begin{array}{c}-0.123^{* *} \\
(0.0554)\end{array}$ & $\begin{array}{c}-0.123^{* *} \\
(0.0554)\end{array}$ & $\begin{array}{c}-0.122^{* *} \\
(0.0553)\end{array}$ & $\begin{array}{c}-0.118^{* *} \\
(0.0522)\end{array}$ & $\begin{array}{c}-0.067 \\
(0.0426)\end{array}$ \\
\hline Combined elasticity ${ }^{\mathrm{iii}}$ & $\begin{array}{c}-0.651^{* *} \\
(0.2684)\end{array}$ & $\begin{array}{c}-0.601^{* *} \\
(0.2833)\end{array}$ & $\begin{array}{c}-0.784^{* *} \\
(0.3542)\end{array}$ & $\begin{array}{c}-0.652^{* *} \\
(0.2692)\end{array}$ & $\begin{array}{c}-0.639 * * \\
(0.2748)\end{array}$ & $\begin{array}{c}-0.61^{* *} \\
(0.2656)\end{array}$ \\
\hline BG FE & yes & yes & yes & yes & yes & yes \\
\hline Year Dummies & yes & yes & yes & yes & yes & yes \\
\hline Market size & no & no & no & yes & no & no \\
\hline Demographics/voting & yes & yes & yes & yes & no & yes \\
\hline Solarize included & yes & yes & yes & yes & yes & no \\
\hline Missing price proxy & average pric & ighest pric & edonic pric & verage pric & verage pric & verage pric \\
\hline Observations & 10,738 & 10,738 & 10,738 & 10,738 & 10,738 & 10,099 \\
\hline
\end{tabular}

Note: Dependent variable is number of residential PV installations. Unit of observation is block group-year. All other variables are the same as in Table 6. Standard errors are obtained by the delta method. $p<0.1\left(^{*}\right), p<0.05\left(^{* *}\right), p<0.01\left({ }^{* * *}\right)$.

i Block bootstrapped standard errors (100 replications), clustered by town.

ii Robust standard errors, clustered by town.

iii Standard errors of combined elasticity coefficients obtained assuming independence of the data generating processes. 
including county fixed effects. The regressors are a Solarize dummy and the set of demographic and voting variables from the baseline specification. We then use the estimated coefficients to predict prices in block groups with zero installations. We are careful in interpreting the estimates in this robustness check (shown in column (II)) due to the likely selection bias that we cannot control for in the hedonic equation. It is nonetheless reassuring to note that the elasticity we obtain of -0.78 is relatively close to our baseline result of -0.65 .

Next, we explore the extent to which the changing market size for solar may affect our results. In particular, the pool of potential buyers continuously declines as more households adopt solar, resulting in a sequential truncation in the distribution of willingness to pay for the consumers remaining in the market. ${ }^{19}$ To test the effects of this endogenous exit of adopters, we estimate an alternative specification in which we control for the market size. We scale the number of Census occupied housing units in each block group-year by the percentage of solar-viable homes in the area calculated from satellite data by GeoStellar, and then subtract the cumulative number of installations in the block group up to that year. This provides a time-varying measure of market size. While the results from this specification should be viewed with caution, as the market size regressor may not be strictly exogenous but only predetermined, they are quite supportive of the robustness of our main model. As shown in column (III) of Table 7, our elasticity estimate is almost identical to the baseline result. Furthermore, the market size variable is not statistically significant effect in either the logit or truncated Poission, with $p$-values of 0.23 and 0.91 , respectively.

In addition, we test the sensitivity of our results to an alternative specification without demographic and voting variables among the regressors (column (IV)). Excluding these variables, we obtain almost identical elasticity estimates as in our baseline logit and truncated Poisson runs. This result is not surprising, given the lack of substantial temporal variation in these variables, as noted earlier.

Lastly, we examine the effect of excluding observations from Solarize campaigns from the analysis (column (V)). This robustness check also provides insight into the origins of our results. We find an elasticity estimate from the truncated Poisson GMM that is of smaller magnitude than the baseline value, while the logit CF is roughly unchanged. The overall implied elasticity from the hurdle model is quite close to our baseline elasticity.

These results underscore the importance of the Solarize campaigns for our observations with multiple installations in a block group-year. Figure 3 shows a histogram of observations with at least one installation. Non-Solarize observations with positive outcomes are largely centered at low counts, while higher-count outcomes are mostly Solarize observations. Hence, when we drop all Solarize observations, our outcome variable is effectively reduced to a binary variable, enabling us to capture most of the variation in the data through the logit component of the hurdle model. This suggests that the hurdle model, as a mix of components that can exploit both binary and zero-truncated count data variation, offers a flexible approach for estimating solar demand in various settings: from emerging markets with few installations to booming higher-demand markets.

${ }^{19}$ We thank an anonymous referee for suggesting this robustness check. 


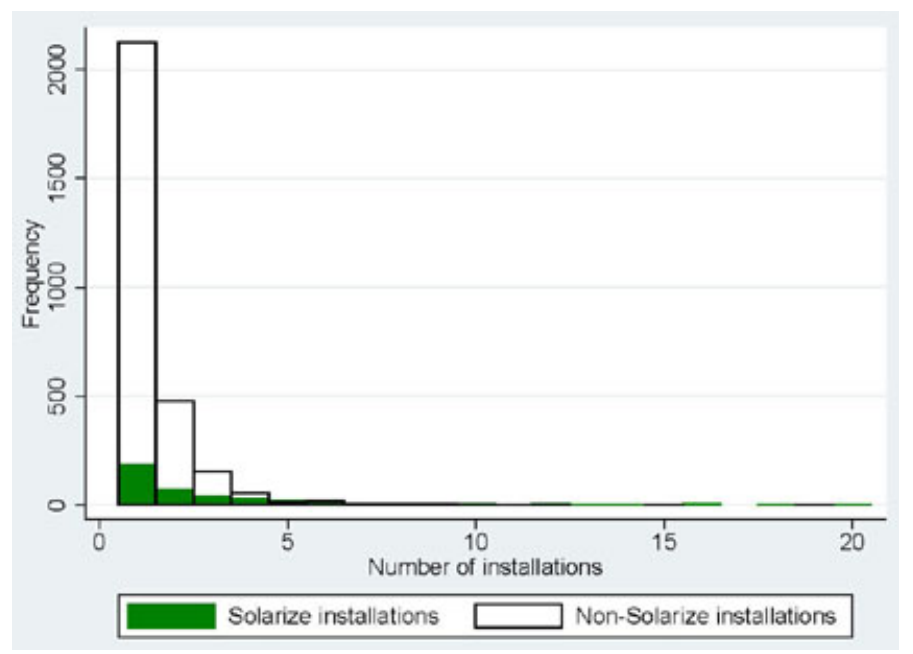

Figure 3. Histogram of the count of installations in the truncated subsample.

\section{Policy analysis}

In this section, we highlight what our results imply for policies in the solar PV market in CT through a set of simple counterfactual simulations. We run three policy counterfactuals: a reduction in the state financial incentives down to Step 6 (recall Table 2), a reduction in state incentives to half of their average level in 2014 (well within the variation in the data), and a waiving of all permitting fees for solar PV systems. These simulations are particularly policy relevant. CT plans is in the process of phasing out financial incentives entirely and at the same time has made efforts to convince municipalities to reduce or entirely waive permitting fees (CEFIA (2013)).

\subsection{Simple pass-through analysis}

As a first step, the above analysis necessitates obtaining a measure of the pass-through of installation costs to customers. While there are some estimates of pass-through in the California solar PV system market, the CT market may be quite different than the California market. Moreover, these estimates based on California data vary widely. For example, Henwood (2014) found a low pass-through rate, while Dong, Wiser, and Rai (2014) and Pless and van Benthem (2017) found nearly complete pass-through. These working papers use similar data, but very different empirical strategies.

Thus, we perform our own simple pass-through analysis for CT, following the standard approach for estimating pass-through of a subsidy or tax on consumer prices (e.g., Sallee (2011)). ${ }^{20}$ We observe the rebate received by each of the 5070 purchased installations in 2008-2014. As noted earlier, the time lag between the submission and approval

\footnotetext{
${ }^{20}$ Note that we do not account for the federal investment tax credit in our pass-through analysis, unlike Pless and van Benthem (2017), because in CT the tax credits are "state rebates" rather than "utility rebates," so they are not viewed as taxable income (see http://solaroutreach.org/wp-content/uploads/2015/ 03/ResidentialITC_Factsheet_Final.pdf).
} 
TABLE 8. Pass-through of Rebates.

\begin{tabular}{lc}
\hline Variable & $\mathrm{I}$ \\
\hline Rebate level & $0.156^{* * *}$ \\
Solarize & $(0.045)$ \\
& $-0.547^{* * *}$ \\
Town FE & $(0.057)$ \\
Year Dummies & yes \\
Observations & yes \\
\hline
\end{tabular}

Note: Dependent variable is prerebate price. Specification is a linear least squares regression. The sample includes only solar contracts with EPBB/HOPBI rebates. Each contract is a separate observation. Town FE refers to town fixed effects. Standard errors are clustered by town. $p<0.1\left(^{*}\right), p<0.05\left(^{(*)}\right), p<0.01\left(^{* * *}\right)$.

of contract applications gives rise to cross-sectional variation in rebate levels. We exploit this variation, along with the temporal variation due to declining incentive levels over time, in order to identify the effect of rebates on prerebate price, after controlling for unobserved region and time effects.

Using installation-level data, we estimate a linear regression of prerebate price (in $\$ / \mathrm{W}$ ) on the rebate level for the first $5 \mathrm{~kW}$ of installed capacity (in $\$ / \mathrm{W}$ ), a Solarize campaign indicator variable, municipality fixed effects, and year dummies. Our results are shown in Table $8{ }^{21}$ The estimated coefficient on the rebate variable can be interpreted as the fraction of a $\$ 1 / \mathrm{W}$ increase in the rebate level that is captured by the installer. A coefficient equal to zero would suggest complete pass-through: the rebate is entirely captured by consumers. A coefficient equal to one would suggest zero pass-through: the rebate is entirely captured by firms. We find a highly statistically significant coefficient on the rebate level of 0.16 , implying a pass-through rate of $84 \%$. In other words, a $\$ 1 / \mathrm{W}$ decrease in installer costs translates into an 84 cents/W decrease in the PV system price.

\subsection{Policy simulations}

For each policy scenario, we quantify the counterfactual number of installations in CT in 2014 and 2015, and compare these to the observed number of installations in 2014 and a projected number of installations in 2015. We limit our simulations to this 2-year period in order to ensure that the demand structure and system characteristics are relatively stable-as in any new technology the distribution of willingness-to-pay is likely to change over the longer run. In this rapidly changing market, extrapolating too far out is not likely to be a useful exercise. These simulations have an important caveat: a model of firm pricing is outside the scope of this paper, so we do not model competition in the market. Thus, just as in any time when a demand elasticity is applied, the simulations

\footnotetext{
${ }^{21}$ We also reran the estimation, aggregating all data at the block group-year level and replacing municipality fixed effects with block group fixed effects. We obtained an almost identical rebate coefficient.
} 
Table 9. Policy simulations.

\begin{tabular}{|c|c|c|c|c|c|c|c|c|}
\hline \multirow[b]{2}{*}{ Year: } & \multicolumn{2}{|c|}{ Baseline } & \multicolumn{2}{|c|}{ Small Reduction } & \multicolumn{2}{|c|}{ Moderate Reduction } & \multicolumn{2}{|c|}{ Permit Fees } \\
\hline & 2014 & 2015 & 2014 & 2015 & 2014 & 2015 & 2014 & 2015 \\
\hline New installations & 1974 & 1994 & 1879 & 1896 & 1803 & 1819 & 1993 & 2013 \\
\hline Added capacity (MW) & 15.43 & 15.59 & 14.69 & 14.10 & 14.22 & 12.08 & 15.59 & 15.74 \\
\hline$\Delta$ installations & & & -95 & -97 & -171 & -175 & 19 & 19 \\
\hline$\%$ change in installations & & & -4.81 & -4.89 & -8.66 & -8.78 & 0.98 & 0.98 \\
\hline$\Delta$ capacity $(\mathrm{MW})$ & & & -0.74 & -0.76 & -1.33 & -1.37 & 0.15 & 0.16 \\
\hline
\end{tabular}

Note: Simulations use a price elasticity estimate of -0.65 from Table 6 and a pass-through rate of $84 \%$, as estimated in Table 8. The "Small Reduction" counterfactual decreases state incentives down to the Step 6 level (see Table 2) in January 2014. The average rebate in this counterfactual is $\$ 0.675 / \mathrm{W}$. The "Moderate Reduction" counterfactual reduces the subsidy to half of its average 2014 level of $\$ 0.935 / \mathrm{W}$ in January 2014. The "Permit fees" counterfactual entirely removes municipal permit fees for solar installations in January 2014, reducing average system costs by $\$ 0.05 /$ W. Further details on the counterfactual simulation methodology are in Online Appendix F in the Supplemental Material (Gillingham and Tsvetanov (2019)).

assume that competition remains constant in this market with the relatively short-run price changes we examine..$^{22}$

Our methodology is straightforward. The CGB database contains installer-reported data on the module, inverter, permitting, and labor costs for each installation. ${ }^{23}$ Since the statutory incidence of the policies falls on the installing firms, we model the policy counterfactuals as a change in the installer's marginal cost. We find the percentage change in the sum of the module, inverter, permitting, and labor costs due to the policy, adjust this by a pass-through rate to estimate the change in price, and then use our estimated elasticity $(-0.65)$ to calculate the percent change in the number of installations. This is then converted into total number of new installations and additional installed capacity in MW. Further details of our approach used for the counterfactual simulations are in Online Appendix F in the Supplemental Material (Gillingham and Tsvetanov (2019)).

The results of our simulations are shown in Table 9. In the baseline, state policies are assumed to remain unchanged and system prices are affected only by the falling global costs of PV components. Hence, projected installations and added capacity for 2015 are slightly higher than the observed numbers in 2014. In the "Small Reduction" counterfactual, the rebate offered by the state is reduced down to Step 6 in the rebate schedule in Table 2, lowering the average incentive amount in 2014 from the observed $\$ 0.935 / \mathrm{W}$ to $\$ 0.675 / \mathrm{W}$. In the "Moderate Reduction" counterfactual, state incentives are cut in half, resulting in an average rebate of $\$ 0.468 / \mathrm{W}$. Finally, the "Permit Fees" counterfactual simulates a decrease in average PV system costs from waiving all municipal permit fees. This amounts to a reduction in average system costs by approximately $\$ 0.052 / \mathrm{W}$ in 2014 .

The "Small Reduction" simulation reveals a $4.8 \%$ decrease in the number of new PV installations in CT during 2014 relative to the number observed, and $4.9 \%$ in 2015.

\footnotetext{
${ }^{22}$ Firms in this market generally compete throughout the state, although they may sometimes focus on certain more narrow regions. We assume that the pass-through rate is constant across the state.

${ }^{23} \mathrm{We}$ are not entirely confident in these reported cost estimates in the dataset, so we also use the module and inverter price indices instead of the reported module and inverter costs. We find very similar results.
} 
This would imply 95 fewer installations in 2014 and 97 fewer in 2015, and is equivalent to a reduction in added PV capacity of $0.74 \mathrm{MW}$ in 2014 and $0.76 \mathrm{MW}$ in $2015 .^{24}$ The "Moderate Reduction" simulation shows much larger impacts on new installations and capacity. The results suggest a decrease in adoption by 171 installations in 2014 and 175 installations in 2015 (1.33 MW in 2014 and 1.37 MW in 2015). If CT succeeded in eliminating municipality permit fees, the number of installations would have been increased by roughly $1 \%$ in both 2014 and 2015 . This amounts to approximately 51 additional installations in each year (0.15 MW in 2014 and $0.16 \mathrm{MW}$ in 2015). Of course, this may be an underestimate of the effect of eliminating permitting fees, since it does not account for the reduced paperwork and associated labor costs from expedited permitting, which likely would occur with a reduction or elimination of the fees. Such additional cost reductions may also be passed on to consumers, increasing the effect.

\subsection{Cost-effectiveness of subsidies}

Our above results can be used to provide insight into the cost-effectiveness and welfare implications of the subsidy policy in CT. We focus on direct program costs (dollar value of subsidies), as in Davis, Fuchs, and Gertler (2014). A quick calculation reveals that the cost of the subsidy is $\$ 3.03$ of state dollars per additional watt installed (in 2014 dollars). Assuming all consumers take the full $\$ 7500$ federal tax credit, this implies a total state and federal program cost of $\$ 4.95$ per watt. ${ }^{25}$ To determine the benefits from a watt of installed solar capacity, we calculate the average annual electricity generation from a PV system in CT. We use the National Renewable Energy Laboratory's "PVWatts" solar electricity calculator for four different locations across CT and average the resultant output. ${ }^{26}$ We assume a 25-year lifespan of an average installed system, which is in line with both the standard warranty offered by most manufacturers ${ }^{27}$ and the assumptions made by the CGB in calculating lifetime electricity generation for an average system. This yields an average lifetime electricity generation of $32.26 \mathrm{kWh}$ per watt of installed capacity, implying a short-run program cost of $\$ 0.094 / \mathrm{kWh}$ generated $(\$ 0.153 / \mathrm{kWh}$ when including the federal tax credit).

There are two sources of avoided pollution from installing solar PV systems: greenhouse gas emissions and local air pollutants. The amount of avoided pollution depends on assumptions about the type of generation that is displaced by solar PV both now and for the next 25 years. The average carbon dioxide emissions rate in the Northeast is estimated to be 0.000258 tons of $\mathrm{CO}_{2}$ per $\mathrm{kWh}$ (Graff Zivin, Kotchen, and Mansur (2014)). Assuming this holds for the next 25 years, the lifetime cost-effectiveness would be $\$ 364 / \mathrm{tCO}_{2}\left(\$ 594 / \mathrm{tCO}_{2}\right.$ when including the federal credit). If we assume that the CT

\footnotetext{
${ }^{24}$ The simulation results assume that the increased adoptions are not simply "pulled-forward" from future adoptions, which is reasonable since there is a large base of potential adopters and the subsidies continued through 2015.

${ }^{25}$ Note that state policymakers find this to be irrelevant.

${ }^{26}$ See http:/ / pvwatts.nrel.gov. The locations we use are New London, North Canaan, Putnam, and Stamford. The calculations account for reduction in output due to periods of no sunlight, as well as loss of generation during conversion from direct to alternating current power.

${ }^{27}$ See, for example, http://energyinformative.org/solar-panel-warranty-comparison.
} 
electricity grid will continue to become less carbon intensive over time, this estimate will be correspondingly higher. While there are numerous caveats to this simple calculation, including the social cost of public funds, the utility consumers receive, profits for installers, intermittency issues (Gowrisankaran, Reynolds, and Samano (2016)), uncertainty in future electricity generation, and spillovers in learning-by-doing at the localized level (Bollinger and Gillingham (2016)), it is notable that this estimate is much above the IAWG (2013) central value of the social cost of carbon of $\$ 42 / \mathrm{tCO}_{2}$ (in 2014 dollars). ${ }^{28}$

\section{Conclusions}

This study estimates the demand for solar PV systems using a new empirical approach: a Poisson hurdle model with fixed effects and instrumental variables. This approach allows us to tackle several key challenges that arise in modeling count data in the diffusion of any new technology. Specifically, it addresses unobserved heterogeneity at a fine geographic level, excess zeros in the outcome variable, and the endogeneity of price. In addition to the adoption of new technologies, we also expect this approach to be useful in a variety of other settings, such as the demand for health care in hospital units.

We estimate the price elasticity of demand for solar PV systems in CT over 20082014 to be -0.65 . This estimate is valuable to both policymakers and firms. As module prices continue to drop, it provides useful guidance for forecasting the number of new installations, absent policy changes. It is also very useful for examining changes in policy, in light of continuing policy discussions about phasing out the financial incentive program and reducing municipal permit fees. After estimating a pass-through rate of $84 \%$, we perform counterfactual policy simulations with less generous state incentives. We find that dropping incentives to Step 6 would have reduced the number of installations by $5 \%$ in 2014, while reducing incentives in half would have led to a $9 \%$ drop in installations in 2014. Simple calculations suggest that the direct program cost is $\$ 364 / \mathrm{tCO}_{2}\left(\$ 594 / \mathrm{tCO}_{2}\right.$ including the federal tax credit), significantly higher than the central estimate of the social cost of carbon used by the U.S. government. Other market failures, such as innovation market failures (van Benthem, Gillingham, and Sweeney (2008)), must be significant for the policy to be social welfare-improving.

For firm decision-making, our finding of a price elasticity of -0.65 suggests that consumers are not very price sensitive. Firms can use this knowledge for short-run forecasting of the expected growth of the market. Moreover, in a market with imperfect competition, our estimated pass-through rate of $84 \%$ can provide important guidance to firms for optimal price-setting to maximize profits.

Our results also provide insight into how other policies influence the solar PV market. For example, we find a highly statistically significant effect of the Solarize grassroots campaigns on installations. Moreover, we find that when we exclude all Solarize installations from our analysis, our elasticity estimate remains the same, but the variation identifying it is almost exclusively from the logit specification. This indicates that without Solarize, the data can be treated as binary rather than count data, a finding due to

\footnotetext{
${ }^{28}$ Including benefits from reduced criteria air pollutants does little to change this calculation.
} 
the fact that the Solarize program accounts for nearly all installations in a block groupyear after the first contract. This may not be surprising, due to evidence of neighbor effects in the diffusion of solar PV systems (Bollinger and Gillingham (2012), Graziano and Gillingham (2015)).

Stepping back, this study of demand in the CT solar PV market highlights the intense policy effort to promote the technology, which mirrors efforts in many other U.S. states, European countries, and other countries around the world. As our approach is applicable to evaluating many solar PV incentive programs, we view further policy analyses in similar settings as a promising area for future research.

\section{Appendix A: Consistency of the IV fixed effects truncated Poisson ESTIMATOR}

$\boldsymbol{Y}_{i}^{*}$ is a vector of outcome variables, such that $\boldsymbol{Y}_{i}^{*} \in \mathcal{Y} \subset \mathbb{R}_{+}^{T_{i}^{*}}$ and each element $Y_{i t}$ is independently distributed with truncated Poisson distribution. Let $\boldsymbol{X}_{i t} \in \mathcal{X} \subset \mathbb{R}^{P}$ and $\boldsymbol{\delta}_{2} \in \Delta \subset \mathbb{R}^{P}$. Let $g_{0}(\boldsymbol{y} \mid \boldsymbol{x}, n)$ denote the true conditional distribution of $\boldsymbol{Y}_{i}^{*}$ given $\boldsymbol{X}_{i}$ and $\sum_{t=1}^{T} Y_{i t}$. If our model is correctly specified, then, for some $\boldsymbol{\delta}_{2}^{0} \in \Delta \subset \mathbb{R}^{P}, g\left(\cdot \mid \boldsymbol{x}, n, \boldsymbol{\delta}_{2}^{0}\right)=$ $g_{0}(\cdot \mid \boldsymbol{x}, n)$, for all $\boldsymbol{x} \in \mathcal{X}$ and $n \in \mathcal{N}$. We now show that the conditional maximum likelihood estimator, obtained from the maximization of (15), is a consistent estimator of $\boldsymbol{\delta}_{2}^{0}$.

Lemma A.1. Let $Q\left(\boldsymbol{\delta}_{2}\right)=\mathrm{E}\left[\log g\left(\boldsymbol{Y}_{i}^{*} \mid \boldsymbol{X}_{i}, n_{i}, \boldsymbol{\delta}_{2}\right)\right]$ and $Q_{N}\left(\boldsymbol{\delta}_{2}\right)=\frac{1}{N} \sum_{i=1}^{N} \log g\left(\boldsymbol{Y}_{i}^{*} \mid \boldsymbol{X}_{i}, n_{i}\right.$, $\left.\boldsymbol{\delta}_{2}\right)$. Under the following assumptions:

A1. $\Delta$ is a compact set.

A2. For each $(\boldsymbol{y}, \boldsymbol{x}, n) \in \mathcal{Y} \times \mathcal{X} \times \mathcal{N}, \log g(\boldsymbol{y} \mid \boldsymbol{x}, n, \cdot)$ is a continuous function on $\Delta$.

A3. For all $\boldsymbol{x} \in \mathcal{X}$ and $n \in \mathcal{N}, Q\left(\boldsymbol{\delta}_{2}\right) \neq Q\left(\boldsymbol{\delta}_{2}^{0}\right)$ if $\boldsymbol{\delta}_{2} \neq \boldsymbol{\delta}_{2}^{0}$.

A4. For all $\boldsymbol{x} \in \mathcal{X}, n \in \mathcal{N}$, and $\boldsymbol{\delta}_{2} \in \Delta, \sum_{\boldsymbol{y} \in \mathcal{Y}} g\left(\boldsymbol{y} \mid \boldsymbol{x}, n, \boldsymbol{\delta}_{2}\right)=1$.

A5. The uniform weak law of large numbers holds.

A6. The sequence $\left\{c_{i}\right\}_{i=1}^{N}$ is bounded, that is, $\lim _{N \rightarrow \infty} c_{N}<\infty, \hat{\boldsymbol{\delta}}_{2, \mathrm{CMLE}} \stackrel{p}{\rightarrow} \boldsymbol{\delta}_{2}^{0}$, where $\hat{\boldsymbol{\delta}}_{2, \mathrm{CMLE}}=\arg \max _{\boldsymbol{\delta}_{2} \in \Delta} Q_{N}\left(\boldsymbol{\delta}_{2}\right)$.

Proof. From A1 and A2, it follows that the problem $\max _{\boldsymbol{\delta}_{2} \in \Delta} Q\left(\boldsymbol{\delta}_{2}\right)$ always has a solution. A3 implies that this solution is unique. Using A4 and Jensen's inequality, it can easily be shown that $Q\left(\boldsymbol{\delta}_{2}\right)$ is maximized at $\boldsymbol{\delta}_{2}^{0}$. From A1 and A2, we also know that the problem $\max _{\boldsymbol{\delta}_{2} \in \Delta} Q_{N}\left(\boldsymbol{\delta}_{2}\right)$ always has a solution. Let $\hat{\boldsymbol{\delta}}_{2, \text { CMLE }}=\arg \max _{\boldsymbol{\delta}_{2} \in \Delta} Q_{N}\left(\boldsymbol{\delta}_{2}\right)$. Under A5, $\left|Q_{N}\left(\hat{\boldsymbol{\delta}}_{2, \mathrm{CMLE}}\right)-Q\left(\boldsymbol{\delta}_{2}^{0}\right)\right| \stackrel{p}{\rightarrow} 0$, by the uniform weak law of large numbers. Therefore, $\hat{\boldsymbol{\delta}}_{2, \mathrm{CMLE}} \stackrel{p}{\rightarrow} \boldsymbol{\delta}_{2}^{0}$. Note that A6 is needed to ensure that the sequence of unknown parameters that we do not estimate, $c_{1}, \ldots, c_{N}$, does not contain a high number of extremely large values, which could result in inconsistency of $\hat{\boldsymbol{\delta}}_{2, \text { CMLE}}$.

However, if $\boldsymbol{X}$ is not exogenous, CMLE is no longer consistent. We next show that, in such a setting, the GMM estimator derived from (21) is a consistent estimator of $\boldsymbol{\delta}_{2}^{0}$. 
Lemma A.2. Suppose $\boldsymbol{Z}_{i t} \in \mathcal{Z} \subset \mathbb{R}^{Q}$, where $Q>P$. Let $\psi\left(\boldsymbol{Z}_{i}, \boldsymbol{\delta}_{2}\right)=\boldsymbol{Z}_{i}^{\prime} \boldsymbol{\xi}_{i}$ and $E\left[\psi\left(\boldsymbol{Z}_{i}\right.\right.$, $\left.\left.\boldsymbol{\delta}_{2}^{0}\right)\right]=\mathbf{0}$. Furthermore, let $G\left(\boldsymbol{\delta}_{2}\right)=\left[\mathrm{E}\left[\psi\left(\boldsymbol{Z}_{i}, \boldsymbol{\delta}_{2}\right)\right]^{\prime} \boldsymbol{\Xi}\left[\mathrm{E}\left[\psi\left(\boldsymbol{Z}_{i}, \boldsymbol{\delta}_{2}\right)\right]\right.\right.$ and $G_{N}\left(\boldsymbol{\delta}_{2}\right)=$ $\left[\frac{1}{N} \sum_{i=1}^{N}\left[\psi\left(\boldsymbol{Z}_{i}, \boldsymbol{\delta}_{2}\right)\right]^{\prime} \hat{\boldsymbol{\Xi}}\left[\frac{1}{N} \sum_{i=1}^{N}\left[\psi\left(\boldsymbol{Z}_{i}, \boldsymbol{\delta}_{2}\right)\right]\right.\right.$, where $\hat{\boldsymbol{\Xi}}$ is a symmetric positive semidefinite weight matrix and $\Xi$ is a symmetric and positive definite matrix. Under the following assumptions:

A1. $\Delta$ is a compact set.

A2. For each $z \in \mathcal{Z}, \psi(z, \cdot)$ is a continuous function on $\Delta$.

A3. For all $z \in \mathcal{Z}, \psi\left(z, \boldsymbol{\delta}_{2}\right) \neq \psi\left(z, \boldsymbol{\delta}_{2}^{0}\right)$ if $\boldsymbol{\delta}_{2} \neq \boldsymbol{\delta}_{2}^{0}$.

A4. $\hat{\Xi} \stackrel{p}{\rightarrow} \Xi$.

A5. The uniform weak law of large numbers holds, $\hat{\boldsymbol{\delta}}_{2, \mathrm{GMM}} \stackrel{p}{\rightarrow} \boldsymbol{\delta}_{2}^{0}$, where $\hat{\boldsymbol{\delta}}_{2, \mathrm{GMM}}=$ $\arg \min _{\boldsymbol{\delta}_{2} \in \Delta} G_{N}\left(\boldsymbol{\delta}_{2}\right)$.

Proof. A1 and A2 imply that the problem $\min _{\boldsymbol{\delta}_{2} \in \Delta} G_{N}\left(\boldsymbol{\delta}_{2}\right)$ always has a solution. Let $\hat{\boldsymbol{\delta}}_{2, \mathrm{GMM}}=\arg \min _{\boldsymbol{\delta}_{2} \in \Delta} G_{N}\left(\boldsymbol{\delta}_{2}\right)$. By definition, we know that $\boldsymbol{\delta}_{2}^{0} \in \Delta$ solves the problem $\min _{\boldsymbol{\delta}_{2} \in \Delta} G\left(\boldsymbol{\delta}_{2}\right)$. By A3 and because $\boldsymbol{\Xi}$ is a positive definite matrix, $\boldsymbol{\delta}_{2}^{0}$ is a unique solution to $\min _{\boldsymbol{\delta}_{2} \in \Delta} G\left(\boldsymbol{\delta}_{2}\right)$. Then, using A4 and A5, $\left|G_{N}\left(\hat{\boldsymbol{\delta}}_{2, \mathrm{GMM}}\right)-G\left(\boldsymbol{\delta}_{2}^{0}\right)\right| \stackrel{p}{\rightarrow} 0$. Therefore, $\hat{\boldsymbol{\delta}}_{2, \mathrm{GMM}} \stackrel{p}{\rightarrow} \boldsymbol{\delta}_{2}^{0}$.

\section{Appendix B: Equivalence of CMLE and GMM estimators under Strict} EXOGENEITY

In what follows, we review the equivalence of CMLE and GMM estimators in our setting that only holds under strict exogeneity of the vector of regressors. Suppose $\boldsymbol{X}_{i t} \in \mathcal{X} \subset \mathbb{R}^{P}$. Then, starting from (15), we can express the $P$-dimensional score vector of derivatives of the log-likelihood corresponding to block group $i$ as

$$
\boldsymbol{S}_{i}\left(\boldsymbol{\delta}_{2}\right)=\nabla_{\boldsymbol{\delta}_{2}} \ell_{i}^{P}\left(\boldsymbol{\delta}_{2} \mid \sum_{t=1}^{T} Y_{i t}\right)=\sum_{t \in \mathcal{T}_{i}}\left[Y_{i t}-\phi_{i t}\left(\boldsymbol{X}_{i}, \boldsymbol{\delta}_{2}\right)\right] \boldsymbol{X}_{i t},
$$

where $\phi_{i t} \equiv \frac{\frac{\partial h_{i}}{\partial \beta_{i t}} \beta_{i t}}{h_{i}}$. Let $\boldsymbol{Y}_{i}^{*} \in \mathcal{Y}$ denote the $T^{*}$-dimensional vector of outcomes in block group $i$, and let $\operatorname{Pr}\left(\boldsymbol{Y}_{i}^{*}=\boldsymbol{y} \mid \boldsymbol{X}_{i}, n_{i}, \boldsymbol{\delta}_{2}\right) \equiv g\left(\boldsymbol{y} \mid \boldsymbol{X}_{i}, n_{i}, \boldsymbol{\delta}_{2}\right)$. Assuming that the model has been correctly specified, $\sum_{\boldsymbol{y} \in \mathcal{Y}} g\left(\boldsymbol{y} \mid \boldsymbol{X}_{i}, n_{i}, \boldsymbol{\delta}_{2}\right)=1$ for all $\boldsymbol{X}_{i}, n_{i}$, and $\boldsymbol{\delta}_{2}$, and it can be shown that the score of the log-likelihood function, evaluated at the true parameter vector $\boldsymbol{\delta}_{2}^{0}$, has a zero conditional mean. Let $S_{i}\left(\boldsymbol{\delta}_{2}^{0}\right)^{(p)}$ denote the $p$ th element of the score vector, corresponding to $\left.\frac{\partial}{\partial \delta_{2}^{p}} \ell_{i}^{P}\left(\boldsymbol{\delta}_{2}\right)\right|_{\boldsymbol{\delta}_{2}=\boldsymbol{\delta}_{2}^{0}}$. Then

$$
\begin{aligned}
\mathrm{E}\left[S_{i}\left(\boldsymbol{\delta}_{2}^{0}\right)^{(p)} \mid \boldsymbol{X}_{i}, n_{i}\right] & =\left.\sum_{\boldsymbol{y} \in \mathcal{Y}} \frac{\partial}{\partial \delta_{2}^{p}} \ell_{i}^{P}\left(\boldsymbol{\delta}_{2}\right)\right|_{\boldsymbol{\delta}_{2}=\boldsymbol{\delta}_{2}^{0}} g\left(\boldsymbol{y} \mid \boldsymbol{X}_{i}, n_{i}, \boldsymbol{\delta}_{2}^{0}\right) \\
& =\left.\sum_{\boldsymbol{y} \in \mathcal{Y}} \frac{\partial}{\partial \delta_{2}^{p}} g\left(\boldsymbol{y} \mid \boldsymbol{X}_{i}, n_{i}, \boldsymbol{\delta}_{2}\right)\right|_{\boldsymbol{\delta}_{2}=\boldsymbol{\delta}_{2}^{0}}
\end{aligned}
$$




$$
=\left.\frac{\partial}{\partial \delta_{2}^{p}}\left(\sum_{\boldsymbol{y} \in \mathcal{Y}} g\left(\boldsymbol{y} \mid \boldsymbol{X}_{i}, n_{i}, \boldsymbol{\delta}_{2}\right)\right)\right|_{\boldsymbol{\delta}_{2}=\boldsymbol{\delta}_{2}^{0}}=0 .
$$

Since the above is true for any element of the score, it follows that

$$
\mathrm{E}\left[\boldsymbol{S}_{i}\left(\boldsymbol{\delta}_{2}^{0}\right) \mid \boldsymbol{X}_{i}, n_{i}\right]=\mathbf{0}
$$

Note that the log-likelihood function is derived after conditioning on the vector of regressors. Therefore, this result would not hold if one or more of the variables in $X$ are endogenous in the model.

Let $\xi_{i t} \equiv Y_{i t}-\phi_{i t}\left(\boldsymbol{X}_{i}, \boldsymbol{\delta}_{2}^{0}\right)$, and let $\boldsymbol{\xi}_{i}=\left(\xi_{i 1}, \ldots, \xi_{i T^{*}}\right)^{\prime}$. By the law of iterated expectations, (B.1) implies that

$$
\mathrm{E}\left[\boldsymbol{X}_{i}^{\prime} \boldsymbol{\xi}_{i}\right]=\mathbf{0},
$$

that is, the expected value of the score leads to the same moment condition as the orthogonality of the regressors to the error term in (19) under strict exogeneity of $X$. Thus, with no endogenous regressors, the sample analog of $\mathrm{E}\left[\boldsymbol{X}_{i}^{\prime} \boldsymbol{\xi}_{i}\right]=\mathbf{0}$ is identical to the firstorder conditions of the conditional likelihood from (15) and yields a GMM estimator that is equivalent to $\hat{\boldsymbol{\delta}}_{2, \text { CMLE }}$.

\section{Appendix C: Monotonicity of $m(\lambda)$}

In order to ensure that $m^{-1}(\cdot)$ is a one-to-one function, we need to show that $m(\lambda)$ is monotonic over the relevant range of $\lambda$ values. In what follows, we prove that, as long as $\lambda$ is positive, the function $m(\lambda)$ is strictly increasing.

Lemma C.1. For any $\lambda>0, m^{\prime}(\lambda)>0$.

Proof. Dropping all subscripts for simplicity, $m^{\prime}(\lambda)=\left[\frac{1}{\lambda}-\frac{e^{-\lambda}}{1-e^{-\lambda}}\right] m(\lambda)=\left[\frac{e^{\lambda}-1-\lambda}{\lambda\left(e^{\lambda}-1\right)}\right] m(\lambda)$. Note that, by the properties of the truncated Poisson model, $m(\lambda)=E_{t}(Y)>0$ for all $\lambda$. Furthermore, $\lambda>0$, which implies that $\lambda\left(e^{\lambda}-1\right)>0$. Hence, we need to ensure that $e^{\lambda}-1-\lambda$ is either positive or negative over the relevant range of $\lambda$.

Let $h_{1}(\lambda)=e^{\lambda}$ and $h_{2}(\lambda)=\lambda+1$ and note that $h_{1}(0)=h_{2}(0)$. Also note that $h_{1}^{\prime}(0)=$ $h_{2}^{\prime}(0)=1$, while, for any $\lambda>0, h_{1}^{\prime}(\lambda)>1=h_{2}^{\prime}(\lambda)$. Hence, $h_{1}(\lambda)>h_{2}(\lambda)$ for all $\lambda>0$, implying that $m^{\prime}(\lambda)>0$ for all $\lambda>0$, which is the relevant range of $\lambda$ in a truncated Poisson model.

\section{REFERENCES}

Andersen, E. B. (1970), "Asymptotic properties of conditional maximum-likelihood estimators.” Journal of the Royal Statistical Society, Series B, 32, 283-301. [288]

Andersen, E. B. (1972), "The numerical solution of a set of conditional estimation equations." Journal of the Royal Statistical Society, Series B, 34, 42-54. [277, 288]

Barbose, G., N. Darghouth, S. Weaver, and R. Wiser (2013), Tracking the Sun VI: An Historical Summary of the Installed Price of Photovoltaics in the United States From 1998 to 2012. Lawrence Berkeley National Laboratory, Berkeley, CA. [281] 
Barbose, G., S. Weaver, and N. Darghouth (2014), Tracking the Sun VII: An Historical Summary of the Installed Price of Photovoltaics in the United States From 1998 to 2013. Lawrence Berkeley National Laboratory, Berkeley, CA. [275]

Berry, S. T., J. A. Levinsohn, and A. Pakes (1995), "Automobile prices in market equilibrium." Econometrica, 63, 841-889. [290]

Blundell, R., R. Griffith, and F. Windmeijer (2002), "Individual effects and dynamics in count data models." Journal of Econometrics, 108, 113-131. [284]

Bollinger, B. and K. Gillingham (2012), "Peer effects in the diffusion of solar photovoltaic panels.” Marketing Science, 31, 900-912. [304]

Bollinger, B. and K. Gillingham (2016), "Learning-by-doing in solar photovoltaic installations.” Working Paper, Yale University. [276, 279, 303]

Burr, C. (2014), "Subsidies, tariffs and investments in the solar power market." Working Paper, University of Colorado. [277]

Cameron, A. C. and P. K. Trivedi (2013), Regression Analysis of Count Data, second edition. Cambridge University Press, Cambridge, MA. [276, 286]

CEFIA (2013), "Sunrise New England: Final project report.” Clean Energy Finance and Investment Authority Report. [279, 299]

Chamberlain, G. (1980), "Analysis of covariance with qualitative data." Review of Economic Studies, 47, 225-238. [277, 288]

Chen, X., H. Hong, and M. Shum (2007), "Nonparametric likelihood ratio model selection tests between parametric likelihood and moment condition models." Journal of Econometrics, 141, 109-140. [289]

Davis, L., A. Fuchs, and P. Gertler (2014), "Cash for coolers: Evaluating a large-scale appliance replacement program in Mexico.” American Economic Journal-Economic Policy, 6, 207-238. [302]

Dong, C., R. Wiser, and V. Rai (2014), "Incentive pass-through for residential solar systems in California.” Lawrence Berkeley National Laboratory Report. [299]

Gallop, R. J., R. H. Rieger, S. McClintock, and D. C. Atkins (2013), "A model for extreme stacking of data at endpoints of a distribution: Illustration with W-shaped data." Statistical Methodology, 10, 29-45. [286]

Gilles, R. and S. Kim (2017), "Distribution-free estimation of zero-inflated models with unobserved heterogeneity.” Statistical Methods in Medical Research, 26, 1532-1542. [286]

Gillingham, K. and B. Bollinger (2017), "Social learning and solar photovoltaic adoption: Evidence from a field experiment.” Working Paper, Yale University. [279, 297]

Gillingham, K., H. Deng, R. Wiser, N. Darghouth, G. Barbose, G. Nemet, V. Rai, and C. Dong (2016), "Deconstructing solar photovoltaic pricing: The role of market structure, technology, and policy." The Energy Journal, 37, 231-250. [276] 
Gillingham, K. and T. Tsvetanov (2019), "Supplement to 'Hurdles and steps: Estimating demand for solar photovoltaics." Quantitative Economics Supplemental Material, 10, https://doi.org/10.3982/QE919. [277, 280, 285, 294, 295, 301]

Gowrisankaran, G., S. Reynolds, and M. Samano (2016), "Intermittency and the value of renewable energy." Journal of Political Economy, 124, 1187-1234. [303]

Graff Zivin, J., M. J. Kotchen, and E. T. Mansur (2014), "Spatial and temporal heterogeneity of marginal emissions: Implications for electric cars and other electricity-shifting policies." Journal of Economic Behavior and Organization, 107A, 248-268. [302]

Graziano, M. and K. Gillingham (2015), "Spatial patterns of solar photovoltaic system adoption: The influence of neighbors and the built environment." Journal of Economic Geography, 15, 815-839. [280, 281, 304]

Greene, W. H. and D. A. Hensher (2010), Modeling Ordered Choices: A Primer. Cambridge University Press. [288]

Gupta, S. and S. Park (2009), "A simulated maximum likelihood estimator for the random coefficient logit model using aggregate data." Journal of Marketing Research, 46, 531542. [290]

Henwood, K. (2014), “Subsidy pass-through in residential solar markets.” Working Paper, University of Chicago. [299]

Hughes, J. E. and M. Podolefsky (2015), "Getting green with solar subsidies: Evidence from the California solar initiative." Journal of the Association of Environmental and Resource Economists, 2, 235-275. [277]

IAWG (2013), Inter-Agency Working Group on Social Cost of Carbon, Technical Support Document: Technical Update of the Social Cost of Carbon for Regulatory Impact Analysis under Executive Order 12866, Washington, DC. [303]

Imbens, G. and J. M. Wooldridge (2007), What's New in Econometrics? Lecture 6: Control Function and Related Methods. NBER Summer Institute. [285]

Jiang, R., P. Manchanda, and P. E. Rossi (2009), "Bayesian analysis of random coefficient logit models using aggregate data." Journal of Econometrics, 149, 136-148. [290]

King, G. (1988), "Statistical models for political science event counts: Bias in conventional procedures and evidence for the exponential Poisson regression model." American Journal of Political Science, 32, 838-863. [284]

Kitazawa, Y. (2012), "Hyperbolic transformation and average elasticity in the framework of the fixed effects logit model.” Theoretical Economics Letters, 2, 192-199. [293]

Kitazawa, Y. (2014), "Consistent estimation for the full-fledged fixed effects zero-inflated Poisson model.” Discussion Paper No. 66, Kyushu Sangyo University. [286]

Majo, M. C. and A. H. O. van Soest (2011), "The fixed-effects zero-inflated Poisson model with an application to health care utilization." Discussion Paper 2011-083, Tilburg University. [277, 289] 
Min, Y. and A. Agresti (2005), "Random effect models for repeated measures of zeroinflated count data.” Statistical Modelling, 5, 1-19. [286]

Mullahy, J. (1986), "Specification and testing of some modified count data models." Journal of Econometrics, 33, 341-365. [286]

Mullahy, J. (1997), "Instrumental-variable estimation of count data models: Application to models of cigarette smoking behavior." Review of Economics and Statistics, 79, 586593. [276]

Neelon, B., P. Ghosh, and P. F. Loebs (2013), "A spatial Poisson hurdle model for exploring geographic variation in emergency department visits." Journal of the Royal Statistical Society: Series A, 176, 389-413. [286]

Neyman, J. and E. L. Scott (1948), "Consistent estimates based on partially consistent observations." Econometrica, 16, 1-36. [284]

Olley, G. S. and A. Pakes (1996), "The dynamics of productivity in the telecommunications equipment industry." Econometrica, 64, 1263-1297. [291]

Petrin, A. and K. Train (2010), "A control function approach to endogeneity in consumer choice models." Journal of Marketing Research, 47, 3-13. [290, 291]

Pless, J. and A. van Benthem (2017), “The suprising pass-through of solar subsidies.” NBER Working Paper 23260. [276, 299]

Pohlmeier, W. and V. Ulrich (1995), "An econometric model of the two-part decisionmaking process in the demand for health care." Journal of Human Resources, 30, 339-361. [276]

Rasch, G. (1960), Probabilistic Models for Intelligence and Attainment Tests. Danish Institute for Educational Research. [277, 288]

Rasch, G. (1961), “On general laws and the meaning of measurement in psychology.” In Proceedings of the Fourth Berkeley Symposium on Mathematical Statistics and Probability 4, 321-333, Univ. California Press, Berkeley, CA. [277, 288]

Rogers, E. and S. Sexton (2014), "Effectiveness of subsidies for residential rooftop solar adoption: Lessons from California.” Working Paper, North Carolina State University. [277]

Sallee, J. (2011), “The surprising incidence of tax credits for the Toyota Prius.” American Economic Journal: Economic Policy, 3, 189-219. [277, 299]

Santos Silva, J. M. C. and F. Windmeijer (2001), "Two-part multiple spell models for health care demand." Journal of Econometrics, 104, 67-89. [276]

Santos Silva, J. M. C., S. Tenreyro, and F. Windmeijer (2015), “Testing competing models for non-negative data with many zeros.” Journal of Econometric Methods, 4, 29-46. [293]

Shaw, S., R. Fahey, and P. Solomon (2014), "Progress report: CEFIA residential solar investment program.” Report, The Cadmus Group, Inc. [278, 279] 
Terza, J. V. (1998), "Estimating count data models with endogenous switching: Sample selection and endogenous treatment effects." Journal of Econometrics, 84, 129-154. [276] van Benthem, A., K. Gillingham, and J. Sweeney (2008), "Learning-by-doing and the optimal solar policy in California.” The Energy Journal, 29, 131-151. [303]

Vuong, Q. H. (1989), "Likelihood ratio tests for model selection and non-nested hypotheses.” Econometrica, 57, 307-333. [289]

Windmeijer, F. (2008), “GMM for panel data count models." In The Econometrics of Panel Data (L. Mátyás and P. Sevestre, eds.). Springer-Verlag, Berlin, Heidelberg. [276, 277, 288]

Windmeijer, F. and J. M. C. Santos Silva (1997), "Endogeneity in count data models: An application to demand for health care." Journal of Applied Econometrics, 12, 281-294. [276]

Winkelmann, R. (2004), "Health care reform and the number of doctor visits-An econometric analysis." Journal of Applied Econometrics, 19, 455-472. [276]

Wooldridge, J. (2002), Econometric Analysis of Cross Section and Panel Data. MIT Press, Cambridge, MA. [284]

Yang, S., Y. Chen, and G. M. Allenby (2003), "Bayesian analysis of simultaneous demand and supply." Quantitative Marketing and Economics, 1, 251-275. [290]

Co-editor Peter Arcidiacono handled this manuscript.

Manuscript received 8 July, 2017; final version accepted 7 February, 2018; available online 1 May, 2018. 